\title{
Identidad étnica y muerte: torres funerarias (chullpas) como símbolos de poder étnico en el altiplano boliviano de Pakasa (1250-1600 d. C.)
}

Identité ethnique et mort : les tours funéraires (chullpas) en tant que symboles de pouvoir ethnique sur l'altiplano bolivien de Pakasa (1250-1600 ap. J.C.) Ethnic identity and death: funerary towers (chullpas) as symbols of ethnic power symbol on the bolivian altiplano of Pakasa (AD 1250-1600)

\section{Risto Kesseli y Martti Pärssinen}

\section{OpenEdition}

\section{Edición electrónica}

URL: http://journals.openedition.org/bifea/4936

DOI: 10.4000/bifea.4936

ISSN: 2076-5827

Editor

Institut Français d'Études Andines

Edición impresa

Fecha de publicación: 1 diciembre 2005

Paginación: 379-410

ISSN: 0303-7495

Referencia electrónica

Risto Kesseli y Martti Pärssinen, « Identidad étnica y muerte: torres funerarias (chullpas) como símbolos de poder étnico en el altiplano boliviano de Pakasa (1250-1600 d. C.) », Bulletin de I'Institut français d'études andines [En línea], 34 (3) | 2005, Publicado el 08 diciembre 2005, consultado el 01 diciembre 2020. URL : http://journals.openedition.org/bifea/4936 ; DOI : https://doi.org/10.4000/bifea. 4936

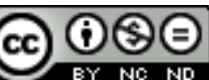

Les contenus du Bulletin de l'Institut français d'études andines sont mis à disposition selon les termes de la licence Creative Commons Attribution - Pas d'Utilisation Commerciale - Pas de Modification 4.0 International. 


\title{
Identidad étnica y muerte: torres funerarias (chullpas) como símbolos de poder étnico en el altiplano boliviano de Pakasa (1250-1600 d. C.)
}

\author{
Risto Kesseli* \\ Martti Pärssinen ${ }^{* *}$
}

\begin{abstract}
Resumen
En este artículo los autores describen varias tradiciones de construcción de chullpas dentro del área histórica de Pakasa. Demuestran que existe en realidad una fuerte correspondencia entre los estilos arquitectónicos de torres funerarias y los territorios de ciertos grupos étnicos en el altiplano boliviano prehispánico. Al parecer, cuando la tradición chullparia se generalizó repentinamente en el siglo XIV, el señorío de Pakasa no era todavía tan uniforme como describen los documentos de la época de Conquista española. Además, demuestran que el estilo de mampostería incaica en las chullpas redondas puede tener sus raíces en el área suroeste de Pakasa o bien en Lupaca. No obstante, las chullpas decoradas de adobe parecen haber sido construidas básicamente durante la época Inca. En general, el artículo contribuye al debate teórico sobre la correspondencia entre la identidad étnica y la cultura material.
\end{abstract}

Palabras clave - arqueología andina, historia colonial, costumbres funerarias, muerte, chullpas, identidad étnica, patrimonio cultural, inca, aymara, puquina, Titicaca

Identité ethnique et mort : les tours funéraires (chullpas) en tant que symboles de pouvoir ethnique sur l'altiplano bolivien de Pakasa (12501600 ap. J.C.)

\section{Résumé}

Dans cet article les auteurs décrivent plusieurs techniques de construction des chullpas au sein du territoire historique de Pakasa. Ils démontrent qu'il existe en réalité une forte corrélation entre les

* Departamento de Arqueología, Apartado 59, Fl-00014 Universidad de Helsinki, Finlandia. E-mail: risto.kesseli@helsinki.fi

** Centro Iberoamericano, Apartado 59, Fl-00014 Universidad de Helsinki, Finlandia.

E-mail: martti.parssinen@helsinki.fi 
styles d'architecture des tours funéraires et les territoires de certains groupes ethniques de l'altiplano bolivien préhispanique. II semblerait que lorsque la tradition des chullpas se généralisa brusquement au XIVe siècle, la chefferie Pakasa n'était pas aussi homogène que le décrivent les documents datant de l'époque de la Conquête espagnole. De surcroît, ils démontrent que le style de maçonnerie inca des chullpas rondes a pu trouver ses racines dans la région sud-ouest des Pakasa ou bien chez les Lupaca. Cependant, les chullpas décorées en adobe semblent avoir été construites principalement durant la période Inca. Cet article entend contribuer au débat théorique sur la correspondance entre identité ethnique et culture matérielle.

Mots clés - arquéologie andine, histoire coloniale, coutumes funéraires, mort, chullpas identité ethnique, patrimoine culturel, inca, aymara, puquina, Titicaca

\title{
Ethnic identity and death: funerary towers (chullpas) as symbols of ethnic power symbol on the bolivian altiplano of Pakasa (AD 1250- 1600)
}

\begin{abstract}
In this article, the authors describe several tradicional ways to build chullpas inside the historical area of Pakasa. They prove that it really exists a strong correspondence among the architectonic styles of the funerary towers and the territories of some etnic groups in the prehispanic bolivian plateau. It seems to be that when the chullparian tradition was sudenly becoming more general in the XIV century, the señorío of Pakasa was not as uniform as it was described in the documents of the time of the Spanish Conquest. Besides, they prove that the style of inca rubblework in the round chullpas can have its origin in the south west area of Pakasa as well as in Lupaca. Nevertheless, the scenery chullpas of adobe seem to have been built mostly during the Inca time. In general, the article contributes to the theorical debate about the correspondence between the ethnical identity and the material culture.
\end{abstract}

Key words - andean archaeology, colonial history, customs, undertakers, death, chullpas, ethnic identity, cultural patrimony, Inca, Aymara, puquina, Titicaca

\section{INTRODUCCIÓN}

Jacques Le Goff (1995: 335) escribía que en la historia de las mentalidades humanas los estudios sobre la muerte parecen ser uno de los campos más exitosos. Por su parte, Michel Vovelle (1990: 128-130) describía a los rituales y ritos funerarios como una especie de diálogo entre los vivos y los muertos. En tal sentido, existiría una vinculación muy estrecha entre las prácticas funerarias y las mentalidades religiosas, culturales y étnicas de una sociedad determinada. En el pasado andino esta conexión es obvia y estas prácticas guardan una íntima relación con la jerarquía y las estructuras de poder (e. g. Dillehay, 1995; Harris, 1983; Kaulicke, 2001: 287; Rowe, 1995). Más aún, los cambios en estas prácticas reflejan normalmente cambios muy profundos en las actitudes y valores culturales de la sociedad, acompañados por cambios religiosos e ideológicos. En tal sentido, las prácticas funerarias parecen tener incluso una vinculación mayor con las identidades étnicas que con el uso de ciertas características estilísticas en la cerámica y otros artefactos domésticos (Pärssinen, 1997: 48).

El período comprendido entre el siglo XI y comienzos del XVI AD en el altiplano boliviano ha sido en la actualidad objeto de varios estudios. Para remarcar más la dinámica humana luego de la desaparición de la cultura Tiwanaku, presentaremos en este artículo los resultados obtenidos principalmente en las torres funerarias o chullpas donde se inhumaba a la elite de Pakasa (altiplano boliviano), durante el proyecto Caquiaviri dirigido por Reino Kero, Martti Pärssinen y Juan Faldín 
(co-director) en 1989-1994, así como en el proyecto Chullpa Pacha dirigido por Ari Siiriäinen, Risto Kesseli y Jédu Sagárnaga Meneses (co-director) en 1998-1999. También presentaremos algunos resultados del proyecto «Formaciones y Transformaciones de las Identidades Étnicas en los Andes Centro Sur», iniciado en el 2003 bajo la dirección de Martti Pärssinen, y co-dirigido por Risto Kesseli, Antti Korpisaari, Juan Faldín y Jédu Sagárnaga. En general, las torres funerarias son testimonios muy importantes para los estudios arqueológicos e históricos, ya que son visibles desde lejos, formando parte del paisaje cultural (e. g. Gil García, 2002; Moore, 2004), además de reflejar un pasado étnico del altiplano.

En contraste con el gran número de artículos escritos sobre las chullpas, siguen siendo pocas las dataciones radiocarbónicas tradicionales o de AMS (Accelerator Mass Spectrometry) efectuadas y publicadas por los investigadores. Hemos observado que, precisamente por esta razón, la tipología y la cronología de las chullpas han permanecido bastante confusas, a pesar de algunos esfuerzos serios por tratar de establecerlas (e. g. Rydén, 1947; Hyslop, 1976; 1977). El objetivo de este artículo es plantear alguna correspondencia entre ciertos tipos de chullpas y los mayores grupos étnicos conocidos históricamente en Pakasa y en señoríos vecinos, tomando en cuenta una cronología revisada de las torres funerarias en los Andes centro sur.

En buena parte de los reportes científicos publicados las chullpas son descritas meramente como de forma «cuadrangular»o «rectangular». En cambio, en nuestra investigación consideramos necesario el establecer un valor numérico que facilitara la clasificación de las chullpas y que a la vez nos ayudara a obtener una idea objetiva sobre la relación entre chullpas cuadrangulares y rectangulares dispersas en las diferentes zonas del altiplano boliviano. Para tal propósito, empleamos una fórmula simple: longitud (pared exterior donde se encuentra el vano, $\mathrm{cm}$ ) dividida por ancho (pared exterior, $\mathrm{cm}$ ) menos 1. De este modo, la chullpa cuadrangular ideal recibe el valor 0 , mientras que la chullpa rectangular ideal el valor 1. Sin embargo,

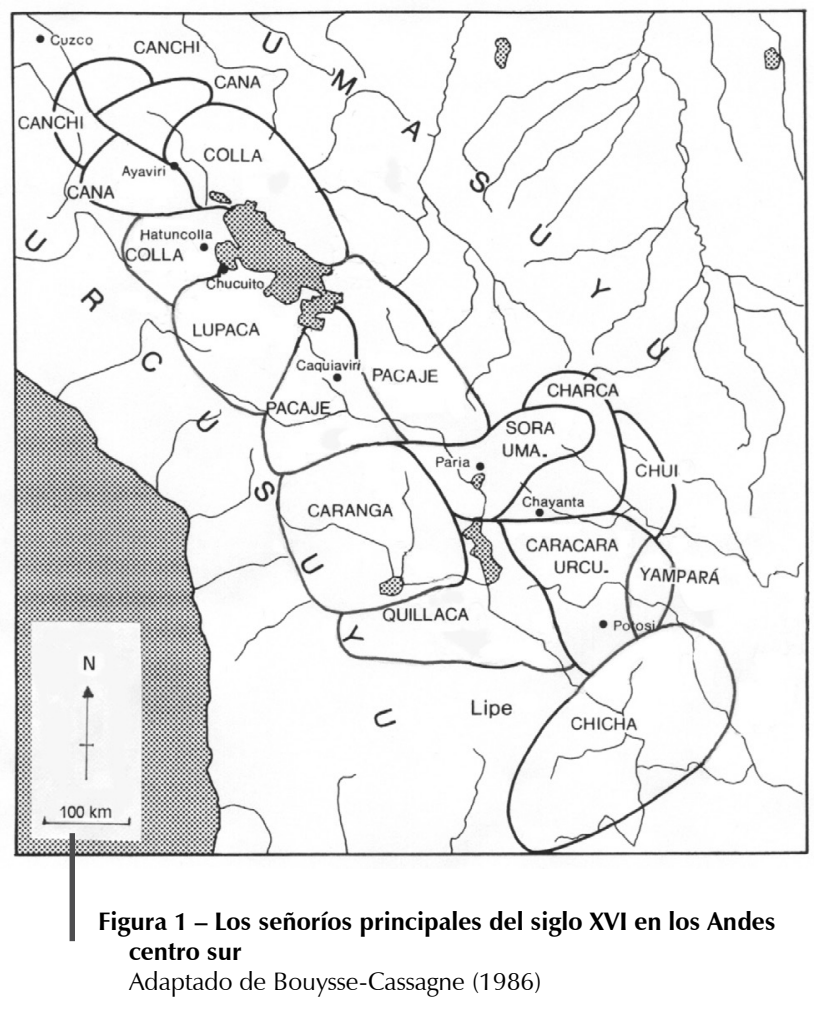
nuestra investigación reveló que también existe un tipo intermedio, al cual se le otorga el valor ideal de 0,5 (oscilando entre 0,26 - 0,75). Este último tipo es común en el territorio de Sora y en el sur de Pakasa (Pacaje) (fig. 1). Aparte de todo lo anterior, conocemos también chullpas hechas de piedra con base redonda, cuando no oval, poligonal o cuadrangular con esquinas redondeadas (Rydén, 1947: 403-476; Tschopik, 1946: 10-17). 


\section{1. Chullpa: monumento mortuorio para personajes de alto estatus}

De acuerdo a la definición general, desde un punto de vista arqueológico, la chullpa (aymara) en el altiplano boliviano es un monumento mortuorio de 1,5-8 $\mathrm{m}$ de altura, generalmente angular o redondo y en forma de torre o caja, destinado a los personajes de gran prestigio. La mayoría de estos monumentos prehispánicos tardíos ha sido construida de adobe, pero también existen varios sitios donde las chullpas han sido hechas de piedra.

En nuestra opinión, la edificación de una chullpa cumplía dos finalidades obvias. Por un lado, los parientes y miembros de las comunidades altiplánicas manifestaban su respeto hacia el difunto, un personaje de gran estatus, malku o hilacata, y a su linaje (ayllu). Por el otro, la chullpa funcionaba como un símbolo en memoria del curaca muerto, expresando su prestigio personal y el de su comunidad, así como su poder en un plano local, regional e incluso interprovincial. En cuanto a su funcionalidad, es probable que las chullpas hayan cumplido el papel de lugares importantes de culto (huaca). Naturalmente, en el paisaje abierto del altiplano también servían, y aún sirven, como un ideal hito o marca territorial.

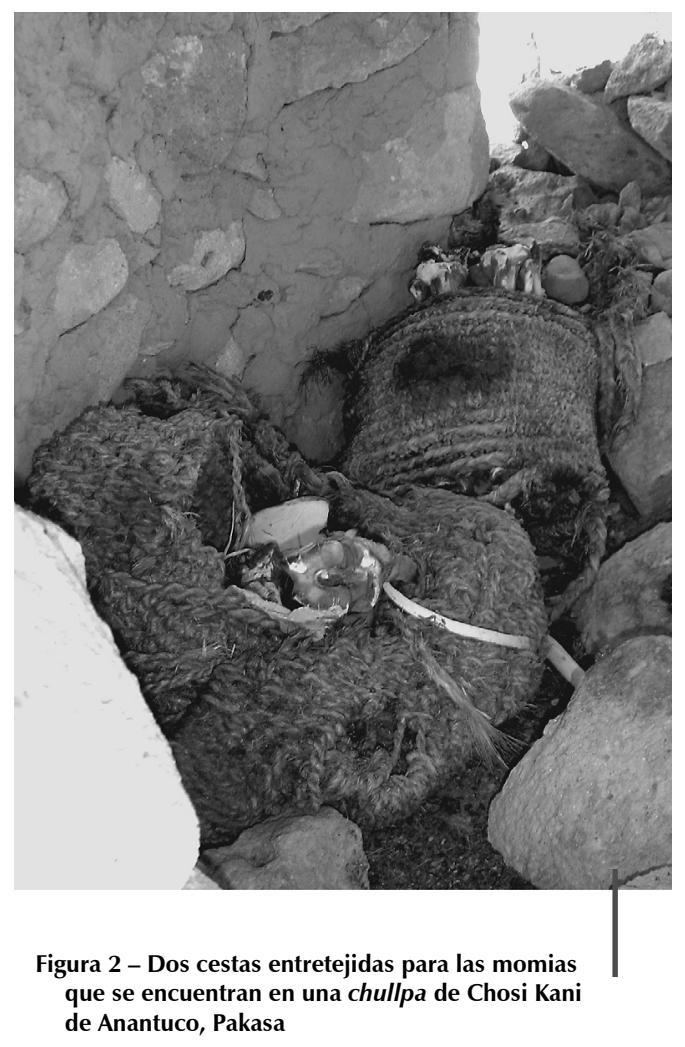

Aunque la función primaria de la chullpa era conservar físicamente el cuerpo del difunto para las generaciones venideras, no era menos importante la función de rendir honores al difunto y su ayllu para mantener la interacción social dentro de la comunidad. Es significativo notar que la sola estructura de la chullpa no bastaba para preservar el cadáver, sino que este debía ser colocado en posición sedente ya sea dentro de una bolsa resistente (de forma capsular; altura 40-80 cm) hecha de textiles o cuero de llama, o a veces en una cesta entretejida hecha de pasto ichu o totora (Forbes, 1870: 239; Gisbert, 2000: 47; Herrmann \& Meyer, 1993: 88-89; Ibarra Grasso \& Querejazu Lewis, 1986: 269; Ponce Sanginés \& Linares Iturralde, 1966: 17-22, figs. 23-26). Además, es importante subrayar que la mayoría de las chullpas son edificios funerarios colectivos (fig. 2), donde no solamente el malku o el jefe de la aldea, sino también sus esposas, hijos y algunos otros parientes cercanos parecen haber sido enterrados. Adicionalmente, algunos sirvientes y otras personas afines parecen haber acompañado como sacrificios humanos al difunto, aunque no siempre voluntariamente (Álvarez, 1998 [1588]: 94). En algunos pocos casos hay un nicho o varios nichos o una cista pétrea subterránea en la cámara, donde el cuerpo podía ser preservado.

La noción de estatus de la chullpa es reforzada por varias crónicas que repiten esta idea. Por ejemplo, al describir Tiwanaku, Cieza de León (1986 [1553]: 284-285) hace mención especial de las torres funerarias que pertenecían a los señores locales:

«Apartados destos edificios [de Tiwanaku], están los aposentos de los Ingas, y la casa donde nasció Mango Inga hijo de Guaynacapa. Y están junto a ellos dos sepulturas de los señores naturales deste pueblo, tan altas como torres anchas y esquinadas, las puertas al nascimiento del sol». 
Otro testimonio relacionado proviene del padre Bartolomé Álvarez (1998 [1588]: 94), quien nos ofrece observaciones minuciosas sobre la tradición funeraria de la chullpa y los sacrificios humanos vinculados a ella en el área sur del Lago Poopó (Ullaga) o la moderna aldea Pampa Aullagas:

«Solían los curacas principales, cuando moría algún principal curaca, hacer que en el aposento del muerto se encerracen las mancebas que habían sido de aquel que estaba muriendo. A las cuales las cercaban otras mujeres; dándoles a comer coca y a beber acua, las hacían morir borrachas y ahogadas desta comida y bebida, diciendo "come, come y bebe presto y mucho, que has de ir a servir al malco — que quiere decir 'señor'—; está de partida y has de ir a servirle allá donde va; que, si tú no vas, no lleva quien le sirva". Y así mataban a muchas, y las enterraban con ellos en sus sepulcros».

Aunque los incas efectuaron varias reducciones para trasladar muchos asentamientos originales a las cercanías de qhapaq ñan, el real camino inca, hubo todavía muchos señores locales que construyeron nuevas torres funerarias cerca de sus asentamientos antiguos. Un caso bien conocido es Cutimbo, el asentamiento preincaico y fortaleza del señorío Lupaca, que aparentemente siguió siendo utilizado todavía en tiempos incas como una necrópolis de los señores Lupaca de Chucuito (Hyslop, 1977: 218-225; Tantaléan Ynga \& Pérez Maestro, 2000: 26-37). Recientemente Mercedes del Río ha documentado un caso similar entre los Sora. En este territorio, Topa Inca obligó a una importante parte de los nativos indios Sora a abandonar su antiguo asentamiento fortificado llamado Sorasora cerca del Lago Poopó y trasladarse al tambo de Paria, construido en las inmediaciones del camino inca. Sin embargo, los dos señores locales llamados Condo y Arizita posteriormente serían sepultados en el interior de las chullpas situadas en Sorasora, «la fortaleza» y necrópolis de sus orígenes. También se ha testificado que aquellas chullpas servían como hitos o marcas territoriales de aquellos malkus principales y sus grupos descendientes o ayllus (Del Río, 1998: 106-107). Más aún, Tristan Platt ha citado un documento temprano que demuestra el esfuerzo colectivo, interprovincial, de construir un gran mausoleo funerario o chullpa para Tata Paria, un importante señor local de Karakara. Eso no es todo, ya que el documento demuestra que realmente la gente de cinco naciones (Karakara, Killaqa, Sora, Chui y Karangas) le construyó a Tata Paria dos chullpas de piedra: una en Macha, la capital inca de Karakara, y la otra cerca de las Salinas de Carata (Platt, 1988: 385-386; cf. también Abercrombie, 1998: 181). La construcción de dos chullpas para un solo personaje podría ser explicada por las importantes funciones simbólicas de la chullpa, considerando el culto a los ancestros y los orígenes, el prestigio del ayllu y las marcas territoriales. Sin embargo, no sabemos cuánta gente acompañó al difunto en su viaje eterno ni tampoco en qué chullpa fue depositada su propia momia.

\section{2. Fenómeno panandino}

Gracias a los conocimientos actuales sobre la distribución de chullpas de diferentes tipos y tamaños, sabemos que la mayor parte de ellas puede ser encontrada en las áreas montañosas de habla aymara, puquina y quechua, en Bolivia y Perú, partiendo de los Andes septentrionales del área peruana de Chachapoyas y Chota-Cutervo (Isbell, 1997: 164 mapa 6.1., 178 mapa 6.2., 204-283; Savoy, 1970; von Hagen, 2002), por el área de la provincia de Canta (Casana Robles, 1976) y alcanzando los grandes lagos salados de Uyuni y Coipasa en Bolivia (Lecoq, 1991: 292321). Más aún, la tradición chullpa no se restringía a las tierras altas, ya que se han encontrado algunas torres funerarias de piedra en las húmedas crestas montañosas del lado oriental de la Cordillera Real (cf. Nordenskiöld, 1953: 85-88; Rydén, 1957: 160-195). Incluso algunas fuentes coloniales tempranas mencionan la presencia de chullpas de adobe en forma de torre en el área selvática del Beni (Recio de Léon, 1906 [1623]: 254-255). Sin embargo, conviene anotar que durante las extensivas inspecciones de campo hechas por Pärssinen (1997: 49-53) alrededor de Chuquisaca, en el señorío Yampará (Bolivia), no se encontró rastro alguno de chullpas. Durante nuestras inspecciones de campo en el 2004, en el Kara Kara del norte, tampoco hemos visto chullpa alguna. Por ello, creemos que el fenómeno de las torres proyectadas sobre la superficie no habría sido totalmente uniforme dentro de los señoríos de habla aymara. 
En nuestra área de investigación en el altiplano boliviano se conoce hasta el momento la existencia de más de cien sitios chullpa (cf. Condarco Morales, 1985: 26, 54, 56-61; 1993: 2; Gil García, 2000: 279; 2001: 72; Isbell, 1997: 164; Kesseli et al., 1999: 338; Ponce Sanginés, 1981: 204; Rydén, 1947: 463). En el área montañosa del norte de Chile se han registrado casi veinte sitios chullpa (Aldunate \& Castro, 1981: 97-104; Dauelsberg, 1983: 73; Muñoz, 1996: 44-58; Muñoz et al., 1987: 67-89; Rivera, 1991: 34-38; Schiappacasse et al., 1989: 181-226). Teniendo en mente que solo una fracción del altiplano ha sido inspeccionada arqueológicamente, se deduce la probabilidad de que el número real de sitios alcance los varios centenares con miles de chullpas de adobe y piedra.

\section{3. Origen de la tradición chullpa}

Según la noción tradicional, las chullpas en los Andes datan del período comprendido entre la desaparición de la cultura Tiwanaku (c. 1000-1100 d. C.) y el inicio de la Conquista española, es decir, durante el Intermedio Tardío (1000/1100-1450 d. C.) y el Horizonte Tardío (1450-1532 d. C.) (Albarracín-Jordan, 1996: 292-296; Hyslop, 1977: 149-170; Ibarra Grasso \& Querejazu Lewis, 1986: 261-269; Lecoq, 1991: 307; Lumbreras \& Amat, 1968: 87-96, 100; Moseley, 1992: 232; Mujica, 1985: 105; Rivera, 1991: 9, 34-38).

Algunos investigadores han intentado explicar los orígenes de la tradición chullpa como una evolución local desde los patrones funerarios Tiwanaku más tempranos. Según esta teoría, a partir de las cistas subterráneas con paredes de piedra al estilo Tiwanaku, surgieron las tumbas con cuello proyectado por encima de la superficie del terreno, dando paso finalmente a las torres funerarias o chullpas (Ayca Gallegos, 1995: 74-76; Albarracín-Jordan, 1996: 292-296). Sin embargo, como Hyslop (1976: 88-92) e Isbell (1997: 166) bien señalan, la ausencia de cerámica Tiwanaku (e. g. kerus o sahumadores) en las cámaras de las chullpas es un argumento contrario a la lógica y la validez de la teoría sobre la evolución gradual. Durante nuestros extensivos estudios de campo en diferentes partes del altiplano (e. g. en Rosario, Anantoco, Jaraque, Huachacalla, Sacabaya, Pumiri, Crucero, Totora, Chuquichampi, Corque, Sevaruyo, Macaya, Sacabaya, Chiarcollo, Orinoca, Andamarca, Challapata, Cala Cala, Sora Sora, Conchiri, Paria, etc.) se confirma esta noción. Más aún, por un lado nuestros estudios en Caquiaviri han demostrado que muchos nuevos asentamientos post-Tiwanaku aparecieron en dicha área a partir de c. $1100 \mathrm{AD}$, indicando claramente que el período Tiwanaku había terminado entre c. 1000-1100 AD, tal como sostiene Alan Kolata, entre otros (Pärssinen, 2003; 2005; Kolata, 1993). Por otro lado, nuevas fechas radiocarbónicas obtenidas de varias torres funerarias muestran que esta nueva tradición chullpa surgió en el área nuclear de la civilización Tiwanaku más temprana sólo después de haber transcurrido unos 200-300 años desde su colapso (Pärssinen, 2005: 121-166). De las 32 torres que hemos sometido a la prueba de radiocarbono, vemos que las chullpas más antiguas son aquellas encontradas en el área norte del Lago Poopó (Sora, Karangas y Pakasa meridional), cuyas fechas se enmarcan dentro de la segunda mitad del siglo XIII, a diferencia de las chullpas más antiguas del área sur del Lago Titicaca, cuyas dataciones corresponden a los comienzos del siglo XIV. Más aún, en ambas áreas geográficas la tradición continuó hasta finales del siglo XVI (Pärssinen, 2003: 238-243, 262-263; 2005: 121-166). Igualmente, las chullpas del área sureña del Lago Poopó parecen ser contemporáneas con las chullpas de Karanga, Sora y sur de Pakasa (Arellano \& Berberian, 1981; Arellano, 2000; Lecoq, 1991; Nielsen, 1998). Solamente las así llamadas chullpas de Toconce, situadas unos $70 \mathrm{~km}$ al norte de San Pedro de Atacama, pueden tener más antigüedad; pero éstas, en un sentido estricto, no pertenecen a la categoría de torres funerarias, ya que carecen de enterramientos humanos (Aldunate \& Castro, 1981; Aldunate et al., 1982; Berenguer et al., 1984; Pärssinen, 2005: 160-161). Por consiguiente, la tradición chullpa en el norte peruano, datada en el período Intermedio Temprano por William Isbell (1997), tampoco puede ser puesta en relación directa con la rápidamente extendida tradición del altiplano sur. Sin embargo, las recientes fechas radiocarbónicas (siglos XIV y XV) obtenidas en Churajón (Arequipa) y Ollantaytambo (Cuzco) indican que la aparición de la tradición chullpa en el sur del Perú estaría relacionada con el mismo fenómeno observado en la cuenca del Lago Titicaca (Szykulski, 1996: 201-219; Bengtsson, 1998: 98-107). 


\section{INVESTIGACIONES EN LOS SITIOS CHULLPA DEL ANTIGUO TERRITORIO PAKASA}

En el área histórica de Pakasa hemos identificado varios estilos de construir chullpas. A pesar de la gran variedad entre las chullpas individuales, podemos distinguir varias tradiciones básicas que serán tratadas en este artículo: (1) las chullpas cuadrangulares de adobe en el área nuclear, (2) las chullpas cuadrangulares de piedra en el norte, (3) las chullpas rectangulares y semi-rectangulares de adobe en el sureste, y (4) las chullpas de piedra tipo Lupaca en el suroeste. A estos datos generales podemos añadir que en el área de Guaqui no se conoce chullpas que tengan la forma de torre (Albarracín-Jordan, 1996: 292-296), y en el caso de Pucarani, Huarina y Achacachi, nos falta aún información apropiada.

\section{1. Caquiaviri}

\section{Provincia Pacajes $\left(17^{\circ} 01^{\prime} \mathrm{S}, 68^{\circ} 36^{\prime} \mathrm{O}\right)$}

El primer tipo de chullpa (cuadrangular de adobe) es típico en Caquiaviri, la capital de la provincia Pakasa durante el período incaico, situada a $53 \mathrm{~km}$ al sur de Tiwanaku, a casi 3920 msnm. Durante la primera fase del proyecto Caquiaviri (1989-1990) se realizaron inspecciones arqueológicas de campo en los alrededores de Caquiaviri, en un área aproximada de $300 \mathrm{~km}^{2}$ (sobre la estrategia de investigación, $c f$. Pärssinen 1997: 257-258). Una gran parte del área de inspección arqueológica estaba situada en Hurinsaya, al lado occidental del pueblo de Caquiaviri (fig. 3).

De acuerdo a la tradición oral, registrada probablemente entre 1585 y 1589 (años en que, según se sabe, Mercado de Peñalosa había fungido dos veces como corregidor de Pakasa), Caquiaviri era «[...] un pueblo muy antiguo y nadie sabe quién la fundó [...]» (Mercado de Peñalosa, 1885 [1585-1589]: 53). Nuestras propias observaciones arqueológicas señalan que Caquiaviri fue fundada, por un lado, después del colapso de Tiwanaku, dada la total ausencia de cerámica estilo TiwanakuPuro o Clásico en el pueblo actual o en sus cercanías; por el otro, las dos fechas radiocarbónicas (Ua-2324, 840 \pm 70 ; Ua-2325, 910 \pm 90 ) obtenidas en la excavación de los cimientos de una casa inca rectangular en Tiquischullpa de Caquiaviri indican que el pueblo pudo haber sido establecido muy poco

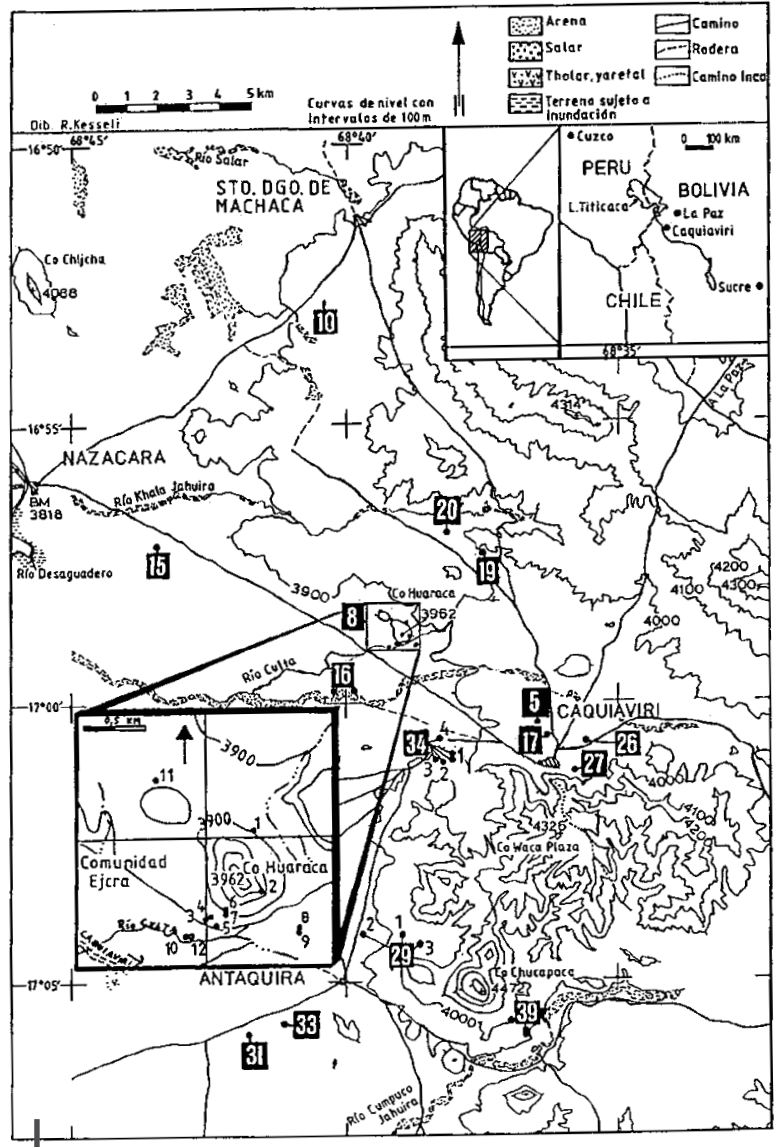

Figura 3 - Mapa de distribución de las torres funerarias en Caquiaviri

№ 8 es Cerro Huaraca, 10 Visamaypata, 19-20 Kari Alta y 34 Ticorini. 
después del colapso de Tiwanaku (Pärssinen \& Siiriäinen, 1997: 257). La muestra más antigua, obtenida del piso quemado del edificio, corresponde a los años 1030-1183, 1188-1209, calibrados con 1 sigma (Pärssinen \& Siiriänen, 1997: 265, Tabla 1).

En un sentido topográfico, las chullpas de Caquiaviri están situadas generalmente al pie de una montaña, o en su ladera más baja, o en la cima de una colina baja, pero nunca en la cumbre de una montaña. De otro lado, también hay chullpas en llanuras abiertas, a corta distancia de ríos pequeños, cuya agua era indispensable para la elaboración de adobes.

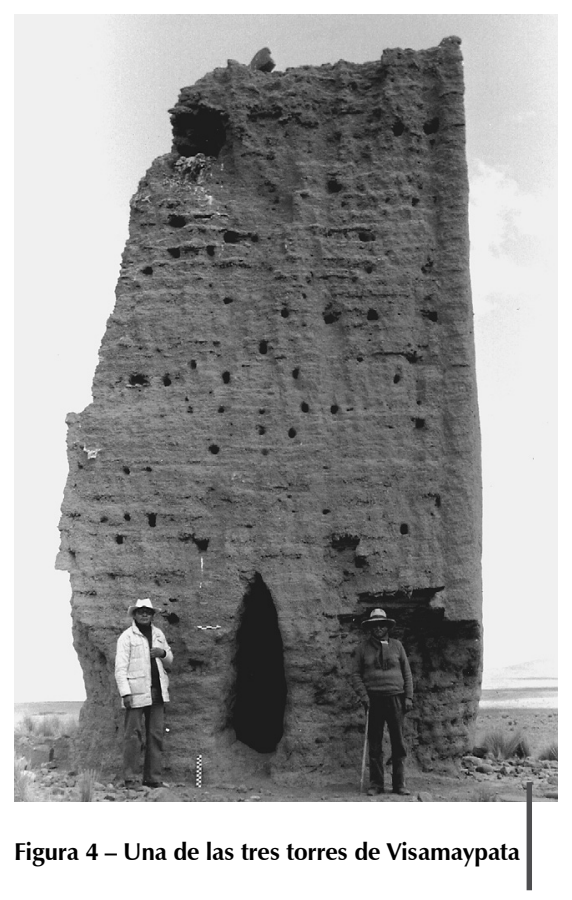

Aunque con mayor frecuencia las chullpas han sido construidas individualmente, en ocasiones se ve grupos de dos o tres chullpas dispuestas lado a lado. Por ejemplo, tres chullpas de Visamaypata habían sido levantadas en línea (las dos primeras lado a lado, la tercera un poco más alejada pero aún en línea) (fig. 4). También tres chullpas (una de ellas totalmente derruida) de Quimsachullpa en Cerro Huaraca están alineadas a intervalos de 1,5 m (fig. 5). En general, la mayor agrupación de chullpas está alrededor de Cerro Huaraca (3 $962 \mathrm{~m}$ ), a casi $7 \mathrm{~km}$ al noroeste de Caquiaviri. En un radio de $1 \mathrm{~km}$ alrededor del cerro pudimos registrar 11 chullpas bien preservadas, más algunas torres totalmente colapsadas, varias tumbas cista subterráneas, algunas pocas sepulturas e inhumaciones hechas en pozas bajas, y tres sitios con gran cantidad de cerámica referida obviamente a asentamientos antiguos. Una concentración menor de chullpas está situada en Ticoniri, unos 3,5 km al oeste de Caquiaviri. En este lugar había una chullpa parcialmente destruida y cinco torres muy destruidas (fig. 3).

Una explicación para la gran concentración de chullpas en Cerro Huaraca, con tumbas cista subterráneas, puede estar en la idoneidad de este cerro cónico para desempeñar la función de una buena marca territorial, sirviendo además como huaca para la población del área caquiavireña, o como un marka qollu, es decir, un

monte sagrado y lugar para sacrificios (cf. también Montaño Aragón, 1999: 196-197). Es importante anotar que desde la ladera sur de Cerro Huaraca se abre una buena panorámica hacia el sagrado Cerro Sajama (6 542 m; 130 $\mathrm{km}$ al sur). Más áun, según Garcilaso de la Vega, la gente de Caquiaviri tenía una montaña sagrada con bella forma de pan de azúcar, a la que veneraban y utilizaban como fortaleza. Si por un lado no encontramos ninguna evidencia de murallas defensivas de piedra en Cerro Huaraca - tampoco en Cerro Sisuca que también tiene forma de pan de azúcar-, por el otro la necrópolis parece corresponder a la descripción de Garcilaso de la Vega (1976 [1609], I: 126, lib III, cap. ii):

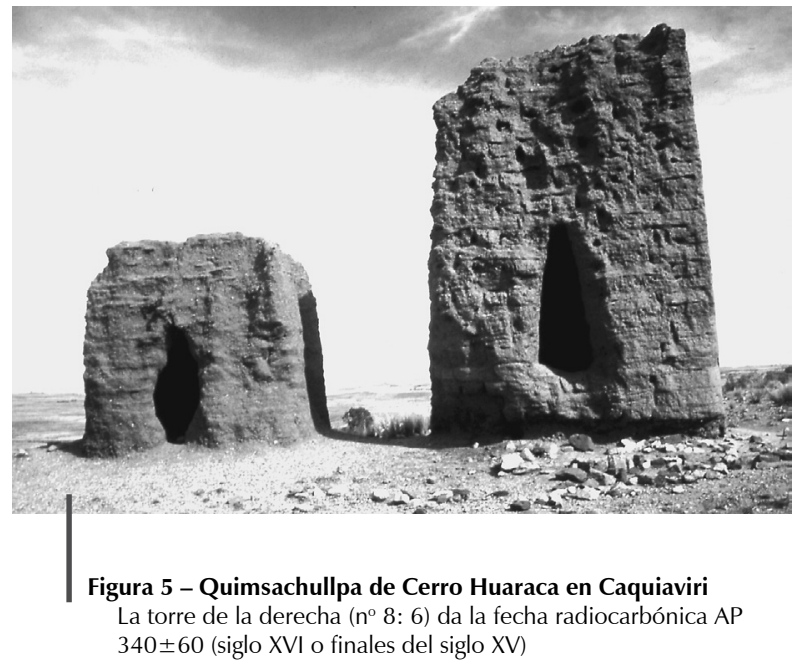


«[...] sabiendo que el Inca iba a conquistarlos, se conformaron y redujeron en un cerro que hay en aquella comarca hecho a mano, alto menos que un cuarto de legua $y$ redondo como un pilón de azúcar, con ser por allí toda la tierra lana. A este cerro, por ser solo y por su hermosura, tenían aquellos indios por cosa sagrada, y le adoraban y ofrecían sus sacrificios».

En toda el área de estudio se registró en total 30 chullpas de adobe bien preservadas, repartidas en 15 sitios, además de numerosas chullpas derruidas por completo. Su altura variaba entre $1,8 \mathrm{~m}$ y $7 \mathrm{~m}$, dependiendo también de su estado de preservación. Las chullpas más grandes en el área de estudio eran tres torres de $7 \mathrm{~m}$ de altura a unos $17 \mathrm{~km}$ al noroeste de Caquiaviri (cf. también Albarracín-Jordan, 1999: fig. 7, 5). Las chullpas de Visamaypata (sitio $\mathrm{n}^{\circ}$ 10) están situadas cerca del camino inca que dividía Caquiaviri en Hurinsaya y Hanansaya. Más aún, su sitio está cerca del límite fronterizo de la cabecera Machaca. Por consiguiente, estas chullpas pueden haber servido también como una demarcación territorial entre divisiones internas, y además, como divisiones de cabecera (marka) externas.

En general, mientras algunas chullpas en el área de Caquiaviri parecen haber sido construidas sobre el suelo desnudo, algunas otras han sido edificadas sobre cimientos de piedra que observan pulcramente la forma de la chullpa (e. g. chullpas $\mathrm{n}^{\circ} 8: 6$ y 8: 11). Ninguna chullpa de piedra fue encontrada. En el área de estudio, todas las chullpas son estructuras individuales, construidas de manera distinta a las demás, si bien comparten algunas características comunes. La forma predominante es casi cuadrangular, porque los valores índice varían entre - 0,18 y 0,33, mientras que el valor medio es 0,09 $(\mathrm{N}=16)$. Por lo tanto, las torres funerarias de Caquiaviri pertenecen claramente al tipo cuadrangular y solamente una chullpa puede ser clasificada como semi-rectangular. Las cámaras mortuorias también eran de forma cuadrangular, a excepción de una de ellas que presentaba una forma redonda.

En las chullpas de Caquiaviri, las cámaras fueron construidas utilizando la técnica de bóveda falsa. Las paredes eran verticales hasta la altura de 1-1,5 m, a partir de la cual se ahusan hacia el centro conformando una bóveda ojival similar a una cúpula. En un sentido arquitectónico, todas las cámaras - menos una - eran de un diseño muy simple. En algunos casos las paredes de las cámaras estaban revestidas con una cubierta de barro. Únicamente en la gran Kumuchullpa $(4,0$ x 3,7 x 5,5 m), no 2 (cf. Pärssinen, 1993: 23, 25), en la ladera suroeste de Cerro Huaraca, hay en la pared occidental signos de un posible nicho trapezoidal.

Dada la alta irregularidad en las formas y tamaños de los adobes, no es de sorprender que hayamos documentado hasta siete diferentes tipos de adobe en las torres de Caquiaviri. Los adobes son rectangulares, cónicos, llanos o redondos, y entre ellos hay normalmente una capa de mortero de casi $2 \mathrm{~cm}$ de espesor. La variedad de adobes sugiere que: 1) las construcciones de estas chullpas fueron básicamente muy individuales, posiblemente sin «reglas» sobre cómo debían aparecer los adobes; y 2) tanto los adobes como los monumentos mismos fueron construidos de acuerdo a las normas que prevalecían en los ayllus locales.

Los vanos están situados usualmente en el medio de la pared este, a nivel del suelo o a un pie de altura. La altura de los vanos varía entre 70 y $243 \mathrm{~cm}$; el ancho promedio es $55 \mathrm{~cm}(\mathrm{~N}=15$, rango de variación 40-90 cm). En otras palabras, en algunas cámaras era necesario arrastrarse, mientras que en otras era posible caminar erguido. La forma de los vanos es trapezoidal (e. g. 8: 11), o alta y estrechamente triangular (e. g. 8: 2), o alta y oval, o termina en un dintel cuyo ancho promedio es de $14 \mathrm{~cm}(\mathrm{~N}=9$, rango de variación de dinteles 6-30 cm) (cf. Escalante, 1994: 325 $334,442,459,460,464-465)$. Un vano muy excepcional puede ser visto en Mayachullpa $\left(\mathrm{n}^{\circ}\right.$ 8: 10); su forma es casi trapezoidal, y tiene solamente $90 \mathrm{~cm}$ de altura. Más aún, está situado en la parte alta de la pared, a $160 \mathrm{~cm}$ desde el nivel del suelo, lo que en caso de no contar con ayuda hacía difícil el acceso a la cámara. Sin embargo, para explicar sus características peculiares no encontramos otro argumento sino la antigüedad (la más antigua de todas las chullpas de Caquiaviri) arrojada por esta torre funeraria en las pruebas radiocarbónicas: (Ua2321) AP 600 \pm 70 , que corresponde en años calibrados al siglo XIV. Sin embargo, todos los 
vanos comparten una característica común y uniforme: la orientación hacia el este. Al medir las ligeras diferencias entre las orientaciones de los vanos en el norte magnético, observamos que la diferencia más grande estaba entre la chullpa Tijllaka $\left(\mathrm{n}^{\circ} 8: 11\right)$ y la chullpa Kari Alta del sur $\left(\mathrm{n}^{\circ}\right.$ 19), cuya istancia es de $4 \mathrm{~km}$. En el primer vano se apunta a 80 grados y en el segundo a 111 grados. Creemos que la diferencia es casual y puede ser aceptada todavía como una variación normal. Llama la atención que este claro dominio de la orientación hacia el este en los vanos de las chullpas de adobe haya sido también objeto de interés para muchos cronistas, hasta el punto que siempre recordaban mencionar esta característica (e. g. Álvarez, 1998 [1588]: 92; Cieza de León, 1986 [1553]: 275; cf. también Heredia Zavala, 1990: 120; Hyslop, 1977: 222; Pärssinen, 1993: 9; Ponce Sanginés, 1958: 15-16; Portugal Ortiz, 1988: 112, 116; Pucher, 1947: 6; Rivera Casanovas, 1990: 82, 85; Rydén, 1947: 360; 1959: 88; Sagárnaga Meneses, 1997: Anexo 2, 202-231; Sever, 1921: 56; Tantalean Ynga \& Pérez Maestro, 2000: 32; Tapia Pineda, 1978: 14, 16-17; Tschopik, 1946: 13; Vásquez, 1937: 55-57).

El que los vanos estén situados siempre en la pared este, sugiere que de trasfondo había alguna creencia ideológica muy fuerte. Hipotéticamente, la explicación ideológica puede ser puesta en relación con la salida del sol y la creencia en su poder vital para mantener la vida y dar luz, calor y fertilidad. Así, el punto cardinal del Este sugeriría un culto al dios Sol, a quien los aymara llamaban por el nombre propio de Villca (Bertonio, 1984 [1612]: 386; Flores Apaza et al., 1999: 146).

En este punto es importante recordar que una cantidad de chullpas similares a las de Caquiaviri (torres cuadrangulares de adobe con sus vanos en la pared este) han sido observadas en toda el área nuclear del territorio Pakasa (entre Callapa y Tiwanaku, y entre Ayo Ayo y Laja/Chuquiapo) (cf. fig. 18). Más aún, en esta misma área las evidencias cerámicas muestran gran uniformidad. Alrededor de las torres funerarias encontramos regularmente cerámica de los estilos Pacajes e Inca-Pacajes.

Finalmente, según Mercado de Peñalosa (1885 [1585-1589]: 61), la característica típica en las chullpas del área de Pakasa era el pintado de sus paredes exteriores. De ser correcta esta aseveración, la desaparición de todas las evidencias en las actuales chullpas de Caquiaviri habría de ser atribuida a la erosión natural y el impacto humano. Sin embargo, anteriormente hemos documentado que en Caquiaviri algunas chullpas no estaban por lo menos pintadas, sino que en lugar de ello habían sido decoradas al usar barro y adobes coloreados secados al sol. Mediante el uso de una composición de adobes grises y rojizos dos chullpas fueron decoradas con composiciones lineales, mientras que una chullpa lo fue con motivos romboidales y en forma de «X», similares a los observados en los textiles y ceramios andinos (Pärssinen, 1993: 25). Más aún, en un caso se presentaban marcas de combinación de adobes rojos y verdes, así como barro rojizo y gris (Pärssinen, 1993: 24). Desafortunadamente, la chullpa estaba en tan malas condiciones de preservación que los motivos decorativos no pudieron ser discernidos.

Hay pocos otros sitios donde las paredes exteriores de las chullpas hayan sido decoradas con adobes o barro de diferentes colores, a saber, rojo, verde, blanco, gris y negro (cf. Gisbert et al., 1994: 427-485; Gisbert, 2000: 42-47; Guerra Gutiérrez, 1982: 12; Kesseli et al., 1999: 347; Kesseli, 2001: 353; Portugal Ortiz, 1988: 115; Sagárnaga Meneses, 1997: 31). Sin embargo, en este artículo volveremos posteriormente a esta cuestión.

\section{2. Qiwaya}

Provincia Los Andes ( $\left.16^{\circ} 20^{\prime} \mathrm{S}, 68^{\circ} 43^{\prime} \mathrm{O}\right)$

Nos trasladamos ahora al sitio de Qiwaya, situado a orillas del Lago Titicaca, $25 \mathrm{~km}$ al norte de Tiwanaku. Este sitio, visitado por nosotros ya en 1992, pasó a convertirse en el punto principal durante el proyecto boliviano-finlandés Chullpa Pacha (1998-1999). Cerca de Qiwaya se halla la isla de Suriqui, a $3 \mathrm{~km}$ hacia el noroeste, en tanto que la isla de Pariti, estudiada en 20032005 por nuestro equipo boliviano-finlandés (Korpisaari \& Pärssinen, 2005), está a 2,5 km en dirección suroeste. Pajchiri, el importante centro Tiwanaku, está situado a $6 \mathrm{~km}$ hacia el sureste, mientras que Lukurmata se localiza a $11 \mathrm{~km}$ hacia el sur. 
Las ruinas arqueológicas de Qiwaya están situadas en una isla en forma de boomerang, conocida también como la isla Cohani (longitud 3,2 km; anchura 500-1,200 m). La agricultura, la ganadería y la pesca son las principales fuentes de ingresos de las casi 70 familias (300 habitantes). Ya que el lago Wiñaymarka, parte sur del Lago Titicaca, es de aguas poco profundas (alrededor de Qiwaya tiene menos de $3 \mathrm{~m}$ ), la totora crece abundantemente cerca de las orillas (Binford et al., 1991: 47-48 y fig. 1; Mourguiart et al., 1995: 173-188). Además, el espejo de agua del lago es objeto de fuertes fluctuaciones (Abbott et al., 1997: 169-180; Binford \& Kolata, 1996: 23-56). Por ello, durante varias décadas ha sido posible llegar hasta el centro del pueblo caminando a través de un estrecho.

El sitio arqueológico, conocido también como Kalauta, cubre una superficie de $1 \mathrm{~km}^{2}$ y está localizado a $500 \mathrm{~m}$ al suroeste del moderno pueblo, al otro lado de la montaña. El sitio se localiza en un valle de unos $700 \mathrm{~m}$ de anchura, y como en un anfiteatro, está dominado por una gran área de campos. Alrededor de dichos campos algunas montañas bajas se elevan con vegetación de arbustos, o con el suelo rocoso parcialmente expuesto, y en todo el contorno hay antiguas terrazas de cultivo, takanas, que hace mucho dejaron de ser mantenidas. La relativa diferencia de altura entre el lago (3 808 msnm en 1998) y el Cerro Kapisi (3 968 msnm) es de 160 m.

Tal vez uno de los documentos históricos más antiguos que menciona a Qiwaya sea un mapa hecho para el virrey Francisco de Toledo en 1573 (Bandelier, 1910: lámina LXXXV). En el mapa aparece un lugar llamado 'Guebaya' que presumimos debe ser el moderno Qiwaya. Sobre estas ruinas algunas observaciones arqueológicas han sido hechas por Alcides D'Orbigny en 1833 (D’Orbigny, 1958 [1839]: 890) y Arthur Posnansky en 1920 (Posnansky, 1957). Además, Wendell Bennett hizo una visita al sitio en 1934 (1950: 95) cuando excavaba en la vecina isla de Pariti.

El significado de la palabra Qiwaya/Khewaya/Quewaya/Quehuaya no ha podido ser descifrado, e incluso la población local desconoce el significado del término. Un dato interesante al respecto lo oímos en 1998 de un joven nativo aymara, Oscar Limachi, cuando hablaba sobre gente (en Qiwaya) que vivió hasta hace unas pocas generaciones en una pequeña isla de totora próxima a Qiwaya. Limachi contaba cómo su abuelo había dicho:

«[...] uro-jaqis en la isla no hablaban aymara sino un idioma como de las chokas. Nosotros le llamamos jut’ i a estas islas». (Sagárnaga Meneses, 1999: 3)

Si el topónimo Qiwaya no es una palabra uruquilla, entonces surge la posibilidad de que sea una palabra puquina. Mejía Xesspe (1979: 45; cf. también Adelaar, 1987: 374; Bernedo Malaga, 1949: 82-86) declara que aquellos nombres de lugares en las áreas de los departamentos de Arequipa y Moquegua (Perú) con los sufijos -waya, -baya y -walla, son nombres toponímicos de origen puquina, y menciona como ejemplo a Quewaya en el Perú. También el cronista Ramos Gavilán afirma que alrededor del Lago Titicaca se hablaba puquina, e. g. 'en las islas', donde además de puquina se hablaba aymara (Ramos Gavilán, 1976: 36, citado en Gisbert, 1999: 8). Pero según el estudio de toponimia realizado por Jonny Bustamante (1998: mapa 1 con 35 nombres de lugares) alrededor de Qiwaya, se desconocen otros nombres de lugares que lleven los sufijos -waya, -baya y -walla. Sin embargo, se sabe que Tiraska, un pueblo cerca de Qiwaya, es el nombre de un ayllu Uru, según los documentos del siglo XVI (Patrones de La Paz, 1684, fols. 87 r. - 94r.).

En nuestra prospección de Qiwaya se incluyen 303 estructuras de piedra, de las cuales $283(93,4$ \%) son casas individuales o complejos de casas; estos últimos comprenden nueve habitaciones en fila y tienen cada uno un pequeño vano rectangular. Si bien el número observable de chullpas de piedra es $20(6,6 \%)$, podemos presumir que algunas más fueron destruidas durante la segunda mitad del siglo XX, ya que a comienzos de la década de 1930 Wendell Bennett (1950: 95) reportaba la presencia de 24 chullpas. En el aspecto arquitectónico, tanto las chullpas como las casas han sido construidas mediante la misma técnica de bloques y mampostería — piedras pequeñas y planas y bloques más grandes han sido colocados juntos muy cuidadosamente usando también barro- . En general, las chullpas están agrupadas en tres sectores, a saber: sector este (A) que agrupaba a 113 estructuras habitacionales y 3 chullpas; sector central (B) con 42 casas y 4 chullpas; y sector oeste (C) con 128 casas y 13 chullpas. 
Todas las chullpas están situadas a solo pocos metros de las casas, por lo que no forman un cementerio separado. Las medidas exteriores promedio son $186 \times 185 \mathrm{~cm}$ y la altura promedio es de $3,0 \mathrm{~m}$. Su forma es claramente cuadrangular, puesto que el valor índice promedio para las 20 chullpas es 0,03. De estas 20 chullpas registradas, casi todas (18) tienen doble cámara, mientras que una de ellas probablemente tiene una sola cámara y otra chullpa tiene tres cámaras. En algunas cámaras se notó argamasa de arcilla en las paredes. La orientación de los vanos es variable: en 11 chullpas los vanos apuntan hacia el oeste, en 3 hacia el sur, y en 6 hacia el sureste.

A fin de obtener mayor información sobre los entierros y materiales chullpa en Qiwaya, se procedió a la excavación en dos chullpas. En el sector oeste (C) decidimos excavar en la chullpa $\mathrm{n}^{\circ} 17$, bien preservada, con doble cámara. Las dimensiones de la cámara inferior en la chullpa $\mathrm{n}^{\circ} 17$ son 1,25 x 1,35 m, y su altura 2,0 m (fig. 6). Aunque el suelo estaba claramente disturbado se recuperó 176 tiestos cerámicos, de los cuales 24 (14\%)

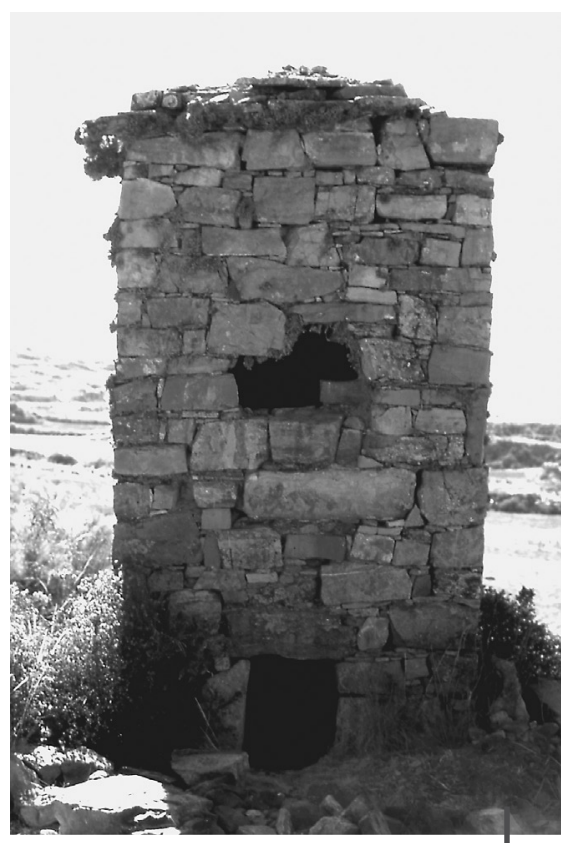

Figura 6 - Chullpa cuadrangular de piedra en Qiwaya construida en la segunda mitad del siglo XIV

Su vano está orientado hacia el suroeste (foto: Antti Korpisaari) tenían decoración geométrica propia de los estilos Pacajes e Inca-Pacajes. Las formas cerámicas incluían pequeñas escudillas de alta calidad y sin decoración, así como ollas globulares de manufactura bastante tosca (Kesseli et al., 1999: 344-347; Korpisaari, 2000). También se encontró una pequeña cesta de mimbre, además de un medallón plano de cobre $(\varnothing 35 \mathrm{~mm})$. De acuerdo al análisis osteológico, los restos humanos hallados correspondían a por lo menos cinco individuos: un varón (edad: 35-40 años), un varón (edad: aprox. 20), una mujer (edad: aprox. 25), dos niños (edad: 1,5 y 3 años, respectivamente) (Villamor, 1999: 1).

Otra excavación fue conducida en el sector este (A), en la cámara de la derruida chullpa A-52. Parecía que esta chullpa había tenido siempre una sola cámara $(1,50 \times$ $1,35 \mathrm{~m}$ ). Durante la excavación dirigida por Sagárnaga Meneses (1999: 56-60) se removió 50-60 cm de suelo antes de llegar al lecho de roca. Debido al anterior saqueo de la tumba, todos los artefactos recuperados (prehispánicos y modernos) en la cámara se hallaban sin contexto o entremezclados en la tierra. En esta cámara, según el análisis osteológico, estaban los huesos de como mínimo 6 adultos (15-55 años de edad) o como máximo 10 adultos. Más aún, se encontraron los huesos de 1-3 infantes menores de 3 años de edad (Villamor, 1998: 8). Además de estos huesos humanos, se encontró huesos animales (83 unidades), e. g. el cráneo de un cánido no identificado, huesos de camélidos no identificados, pájaros, cuyes, peces y algunos huesos de oveja (éstos últimos obviamente como elementos hispánicos) (Villamor, 1998: 8).

La cerámica está dividida entre tiestos precolombinos y modernos. De los 314 tiestos recuperados, había $36(11,5 \%)$ decorados con motivos geométricos pintados mayormente en «negro sobre rojo», mientras que 278 (88,5 \%) carecían de decoración. Entre los tiestos había fragmentos de ollas globulares, grandes vasijas abiertas, y los restos de una vasija globular de cuello estrecho. Entre los hallazgos más raros están un medallón de piedra redondo y perforado, una piedra bola, y los fragmentos de una cesta de mimbre y una cuerda de totora entretejida.

Hemos obtenido dos fechas radiocarbónicas AMS de las chullpas de Qiwaya. La primera muestra proviene del sector oeste $(C)$, de la chullpa C-17 excavada, y la segunda del sector este (A), chullpa A-69. Las muestras de pasto fueron tomadas de la argamasa arcillosa de la pared de la cámara. La primera muestra (Ua-16831) arrojó un resultado de $625 \pm 80$ y la segunda (Ua-16830) 650 \pm 65 , que corresponden a las fechas calibradas AD 1303-1361 ó 1379-1421 
y 1302-1363 ó 1378-1402 (1 sigma, según Stuiver \& Reimer, 1993 y McCormac et al., 2002: Calib Rev4.4), respectivamente. Por consiguiente, en vista de estas fechas, puede afirmarse que las chullpas de piedra en Qiwaya fueron construidas durante el siglo XIV d. C. Más aún, vale anotar que en diferentes partes del sitio se excavó en algunas tumbas cista subterráneas, cuya forma y material recuperado, aunque esparcido, sugieren una fecha del período de transición del Tiwanaku-Tardío al Intermedio-Tardío. En general, en el área de investigación en Qiwaya, se encontró cerámica de los estilos Pacajes, Inca-Pacajes y unos tiestos Tiwanaku en todos los sectores cercanos a las ruinas.

En resumen, lo que consideramos más importante en referencia a las chullpas de Qiwaya es que no obstante su forma cuadrangular, estas hayan sido hechas de piedra en lugar de adobe y, más aún, que no estén orientadas, anónimamente hacia el este. En cambio, la orientación hacia el oeste y el sur es muy común. Nuestra hipótesis es que esta diferencia refleja una identidad étnica muy profunda y separada dentro del área, a diferencia de Caquiaviri y otras áreas meridionales. Sin embargo, similares chullpas de 1-3 pisos son conocidas en Taramaya y Taquiri (Kesseli et al., 2003: 97-120; Rydén, 1947: 343-355) y cerca de Charazani, en la parte oriental de la cuenca del Titicaca (Rydén, 1957). Tal como Stig Rydén (1957: 173-191) ha documentado, también en Charazani el patrón cuadrangular de las chullpas de piedra es el más común, e incluso una chullpa arroja un valor índice de -0,35. Más aún, al igual que en Qiwaya, las chullpas están orientadas hacia el sur, oeste y este, pero no hacia el norte. Históricamente se sabe que muchas de estas áreas adyacentes a las orillas del Lago Titicaca, así como Omasuyu de Pakasa, han sido de habla puquina (Bouysse-Cassagne, 1975: cuadro 1; 1987: passim; Gisbert, 1987: 1-10; Montaño Aragón, 1992: 121-169; Pärssinen, 2005: 242-247; Torero, 1987: 329-372; Wachtel, 1986: fig. 15.4). Por lo tanto, es muy probable que en aquellos tiempos los puquina hayan expresado su distinta etnicidad al construir sus torres funerarias de una manera diferente a los aymara.

\section{3. Kulli Kulli de Sica Sica}

Provincia Aroma $\left(17^{\circ} 24^{\prime} \mathrm{S}, 67^{\circ} 42^{\prime} \mathrm{O}\right)$

Uno de los sitios más grandes de chullpas de adobe en la antigua Pakasa es Kulli Kulli, cerca de la carretera La Paz-Oruro. Las chullpas rectangulares y ligeramente coloreadas están situadas a $13 \mathrm{~km}$ al sureste de Sica Sica y $5 \mathrm{~km}$ al suroeste del pueblo de Lahuachaca sobre una amplia planicie a c. $3800 \mathrm{msnm}$, donde la cría de animales y la agricultura son hoy en día las principales fuentes de subsistencia.

En la historia de investigación podemos encontrar dibujos — recientemente publicados— que ilustran el sitio; dichos dibujos fueron hechos por el diplomático francés Léonce Angrand a finales de la década de 1840 (Mesa et al., 1999:73, 100-101). En ese tiempo parecía haber todavía varias chullpas de tamaño excepcional. En este sitio, Trimborn documentó algunas chullpas durante sus estudios arqueológicos hechos muy posteriormente (Trimborn, 1958: 24-39; 1967: 87-112). Por su parte, Heredia Zavala (1990: 119-122; 1991: 97-114; 1993: 163-171) realizó inspecciones de campo con estudiantes de la universidad UMSA de La Paz a nivel regional. Finalmente, en el año 2000, Ruden y Víctor Plaza del DINAAR, La Paz, realizaron un mapeo del sitio principal y documentaron cada chullpa durante el proyecto de investigación (Plaza \& Plaza, 2000; Plaza, 2003).

En Kulli Kulli hay realmente tres grupos de chullpas: uno en el sitio principal y dos grupos más pequeños en las cercanías. En la década de 1940 había todavía, según Pucher, 74 chullpas dispersas en una superficie de una hectárea, pero el vandalismo, el saqueo de tumbas y la erosión natural han reducido su número a 48 (Pucher, 1947: croquis). El segundo y más pequeño grupo de cuatro chullpas en línea está situado a 260 m al noreste del sitio principal. Más aún, casi $200 \mathrm{~m}$ al suroeste del grupo principal hay seis chullpas más. Es fácil observar que muchas de las chullpas han sido construidas deliberadamente en línea, separadas por pocos metros unas de otras. Los ladrillos de adobe no son uniformemente angulares, sino que frecuentemente se asemejan a «una tortilla enrollada y doblada». 
En nuestra visita a Kulli Kulli (1989 y 1998) no se realizaron mediciones sistemáticas de las torres funerarias. Sin embargo, Trimborn (1958: 30) considera como representativas dos medidas obtenidas en Kulli Kulli: la primera es 3,95 x 2,20 m, altura 4,85 m; y la segunda es 5,45 × 3,10 $\mathrm{m}$, con una altura de $6,40 \mathrm{~m}$. Al aplicar nuestra fórmula, la primera da un valor índice de $0,79 \mathrm{y}$ la segunda 0,76 . Adicionalmente, medimos una chullpa de gran tamaño $(5,50 \times 2,90 \mathrm{~m}$; altura aprox. 5,0 m), que arroja un valor índice de 0,89. Más aún, según las medidas tomadas por Ruden Plaza Martínez (2003: fig. 10) y Victor Plaza de 35 chullpas del grupo principal en Kulli Kulli, el valor índice aritmético promedio es 0,86 lo que nos permite clasificar como rectangular la forma de las chullpas en Kulli Kulli. Más aún, todas las chullpas están reorientadas hacia el este.

Algunos tiestos diagnósticos recuperados alrededor de las chullpas pertenecen a la tradición Altiplano, con vasijas profundas de fondo plano y pequeños jarros con asa vertical. Los motivos geométricos están pintados en «negro sobre rojo» y con frecuencia su lado interior cerca del borde incluye líneas ondulares gruesas, la figura de un nido, candelabros y llamitas. En general, el estilo puede ser clasificado dentro de la categoría Pacajes, pero las variantes Inca-Pacajes parecen ausentarse por completo (cf. Albarracín-Jordan, 1996: 265-266; 1999: fig. 7.2 entre páginas 90 y 91; Heredia Zavala, 1991: 111; Ibarra Grasso \& Querejazu Lewis, 1986: 268; Trimborn, 1958: 36, Abb. 42). Durante nuestra visita al sitio un terrateniente local nos mostró 7 vasijas abiertas, profundas, de fondo plano, de diferentes tamaños (diámetro aprox. 10-15 cm). Nos dijo que dichas vasijas bien cocidas provenían de las chullpas de Kulli Kulli. Algunas de las vasijas parecían datar del período Intermedio Tardío o bien del Horizonte Tardío porque estaban decoradas con motivos geométricos pintados en «negro sobre rojo»; estos motivos ya los habíamos visto en el material recuperado en otros sitios chullpa de Pakasa.

Para la datación radiocarbónica tomamos muestras de tres chullpas en el sitio principal. La primera muestra proviene de la esquina noroeste del sitio. La muestra Ua-2901 dio un resultado de AP $720 \pm 80$, cal d. C. 1264 (1291) 1389, 1 sigma 68,3 \%. La segunda muestra Ua-2902 provenía de la chullpa ubicada en el centro del sitio principal y databa AP 770 75 , cal d. C. 1220 (1279) 1297, 1 sigma 68,3 \%. La tercera muestra viene de la chullpa ubicada en la esquina sureste del

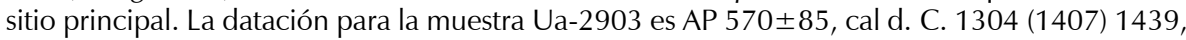
1 sigma 68,3 \% (Pärssinen, 2003: tabla 1; 2005: 159). En vista de estas dataciones sugerimos que las chullpas más antiguas del sitio Kulli Kulli son aquellas situadas en el centro del sitio principal, mientras que las menos antiguas están en los alrededores del cementerio. También es posible que el sitio Kulli Kulli haya alcanzado su extensión actual ya antes de producirse las conquistas

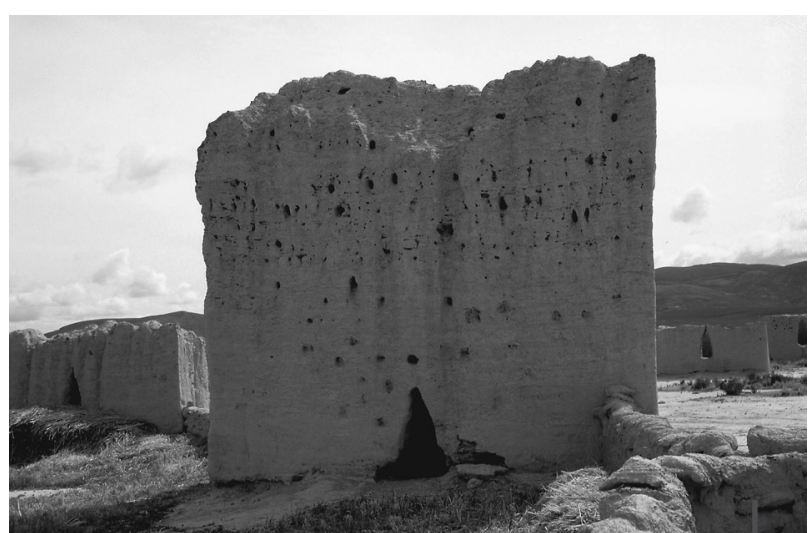

Figura 7 - Torre funeraria construida en la segunda mitad de siglo XIII situada en el centro de la necrópolis de Kulli Kulli incas en este territorio (fig. 7).

En términos generales, las fechas radiocarbónicas sugieren que muchas chullpas de Kulli Kulli serían más antiguas que las chullpas cuadrangulares de Caquiaviri. Sin embargo, lo que consideramos en extremo interesante es la presencia en el interior del territorio Pakasa, en Kulli Kulli, de una de las mayores concentraciones de tumbas funerarias en un solo lugar. Más allá de su forma y valor índice, las chullpas de Kulli Kulli acusan una clara diferencia respecto a las chullpas de la parte central del territorio Pakasa. Estos dos hechos indican que las prácticas funerarias en el área de Sica Sica reflejaban un patrón algo diferente, así como una 
identidad distinta a Caquiaviri. De ser así, podemos postular que la incorporación de Sica Sica bajo la hegemonía de Caquiaviri ocurrió no antes del siglo XV.

\section{4. Cerro Pirapi Chico de Achiri}

Provincia Pacajes $\left(17^{\circ} 16^{\prime} \mathrm{S}, 68^{\circ} 57^{\prime} \mathrm{O}\right)$

Algunas de las más espectaculares chullpas en la provincia de Pakasa están localizadas en las laderas de una antigua fortaleza cerca del actual pueblo de Achiri, en el lado oeste del río Desaguadero. Curiosamente, no hemos encontrado fuentes coloniales tempranas que hagan mención de Achiri o Pirapi. Pero en la obra de Maurtua de 1906-1908 hay «Mapa del Obispado de La Paz», dibujado en 1668, donde Achiri y Caquingora aparecen marcados como pertenecientes a la provincia Pakasa (cf. Ponce Sanginés, 1993: 101; Murra, 1991: 7). Sin embargo, parece muy probable que el área haya pertenecido al distrito de Caquingora, al igual que las minas coloniales de Berenguela, situadas incluso a mayor distancia hacia el oeste de Pirapi (Mercado de Peñalosa, 1885 [1585-1589]: 53). De hecho, Estavan de Lartan (1980 [1608]: 16) escribió que los territorios de Caquingora y Calacoto de Pakasa se extendían hasta Tacora en el moderno Chile:

«[...] en el dicho pueblo de calacoto se sustentan del aguo del dho rrio de maure que nace en los altos de tacora que es una cordillera nebada a donde se acava la jurisdición deste distrito y entra el corregimiento de arica».

Esta interpretación es apoyada también por la tradición oral local, registrada a comienzos del siglo XX, según la cual algunas chullpas de Pirapi pertenecían a la familia de Cusicanqui de Calacoto. Según escribe Posnansky:

«El folklore hace presumir que [las Chullpas grandes de piedra de Pirapi Chico] han sido castillos de los antepasados, de los caciques cusicanqui de Calacoto, los que quizás fueron jefes de mitimayos». (Posnansky, 1920, citado por Camacho T., 1997: 60)

En otras fuentes encontramos que los Cusicanquis de Calacoto eran descendientes de Topa Inca Yupanqui, quien fuera nieto de Felipe Tupac Yupanqui, a quien a su vez le fueron otorgados armas y títulos por Carlos V en 1545 (Escobari de Quarejazu, 1983: 163-166). Durante la reducción española ordenada por Francisco Toledo, parece que la familia se mudó de Caquingora al nuevo pueblo colonial de Calacoto, establecido en el otro lado del Desaguadero y que formaba básicamente un nuevo distrito de Caquingora (Rivera \& Platt, 1978: 102-103). Al mismo tiempo, los españoles procedieron a la reducción de la mitad de otra cabecera de Pakasa, Machaca (actual Jesús de Machaca), hacia el mismo lado del Desaguadero donde estaba Calacoto, constituyendo allí Machaca la Grande (los actuales San Andrés y Santiago de Machaca) y compartiendo con Calacoto el distrito de Berenguela. Sin embargo, antes de la reducción española, el lado occidental del Desaguadero no era un territorio completamente despoblado. Por lo menos, en el caso de Machaca la Grande, el área había sido cedida antiguamente a la religión inca, y posteriormente una mitad de esta área fue entregada, como resultado del juego de ayllusca, al Inca del Cuzco. Después de eso el territorio fue utilizado principalmente para el pastoreo de llamas y alpacas propiedad del Sol y el Inca (Expediente EC-TI-1585-n ${ }^{\circ}$ 7, ANB, citado en Pärssinen, 2005: 236; sobre el juego de aylluscas, cf. especialmente Ziólkowski, 1997: 301-319). Sin embargo, no sabemos si el abuelo de Felipe Tupac Yupanqui llegó a Caquingora como un mitimae, o si fue por medio - lo más probable - de una típica relación matrimonial y una alianza entre el Inca y el señor local, en este caso con el malku de Caquingora (cf. Pärssinen, 1992). De cualquier modo, la presencia de los descendientes del Inca en el altiplano boliviano no resulta del todo extraña, ya que a muchos otros malkus, tal como Christóbal Topa Inga, hijo de Huayna Capac en Copacabana, o aquellos tres descendientes incaicos «con el titulo de yngas» que vivían en Caquiaviri aún en 1686, les fueron conferidos títulos similares por Carlos V (Pärssinen, 2005: 241). 
Lo que aquí parece ser más importante es la asociación de la fortaleza y necrópolis de Pirapi con Caquingora, una de las cabeceras principales del señorío Pakasa, situada en el camino inca entre Caquiaviri y Callapa. Cuando Bernabé Cobo describía la conquista del territorio por el Inca Pachacuti, hizo especial mención de la fortaleza de Caquingora. En las palabras de Cobo (1964 [1653]: 82):

«Quedaron en este jornada [de Pachacuti] puestos en obediencia del Inca todos los pueblos y naciones del contorno de la gran laguna de Titicaca, que de una parte la ciñen las provincias de los Lupacas y Pacasas, y de la otra las del Paucarcolla, Asangaro y Omasuyo, con las islas que tiene la dicha laguna, las cuales en aquel tiempo estaban muy pobladas. Algunos de los pueblos referidos se defendieron valientemente y tuvieron muchos rencuentros con el Inca antes de sujetársele; porque a no pocos se les puso apretado cerco y ellos hicieron fortalezas en que defenderse, como son las de Caquingora y la que vemos en alto cerro del pueblo de Juli, que es cinco murallas de piedra seca unas dentro de otras, adonde los naturales se acogieron y pelearon mucho tiempo defendiéndose $[\ldots] \gg$

La fortaleza de Caquingora, mencionada por Cobo en relación con la campaña temprana del Inca Pachacuti en el territorio de Pakasa, bien puede haber sido la misma fortaleza de Pirapi. Sin embargo, ya que en esta área se conocen otras importantes fortalezas ( $c f$. Huidobro Bellido, 1993: 57-87), nuestra identificación no puede ser considerada inmune a cuestionamientos. Sin embargo, muchos cronistas nos dicen que en tiempos de Topa Inca casi todas las naciones del Collao, incluida Pakasa, se rebelaron contra la autoridad del Cuzco. Topa Inca tuvo que interrumpir su expedición en la amazonía y pacificar la rebelión luego de fieras batallas (e. g. Sarmiento, 1943 [1572]: 225-228). Probablemente fue justo después de esta rebelión que los incas decidieron reorganizar los patrones poblacionales en las áreas de los lagos Titicaca y Poopó, obligando a los lupaca, sora y pakasa, por lo menos, a abandonar muchos de sus antiguos territorios y fortalezas para establecer nuevos asentamientos en o cerca de los nuevos caminos incas. En el caso de Caquingora se declaró simplemente ante un inspector español:

«este pueblo de Caquingora fue poblado por orden de Topa [Inca] Yupangui». (Mercado de Peñalosa, 1885 [1585-1589]: 53)

Esto parece explicar porque Pirapi de Achiri, una fortaleza tan grande, con antiguos asentamientos y necrópolis para una importante sección de los habitantes de Caquingora, desapareciera casi por completo de nuestras fuentes coloniales tempranas. Así, el área habría sido parcialmente despoblada por Topa Inca, y luego de esto serviría solo como una necrópolis y huaca para la población local, mientras el área en sí dependía de los señores del Cuzco.

El sitio arqueológico de Pirapi Grande está situado a $8 \mathrm{~km}$ al sureste del pueblo de Achiri. En realidad, hay dos Pirapis, a saber Cerro Pirapi Grande y Cerro Pirapi Chico. El primero puede ser distinguido desde lejos en el horizonte por su impresionante meseta encima del cerro $(2,0 \mathrm{x}$ $0,3 \mathrm{~km}$ y $4126 \mathrm{msnm}$ ), un lugar ideal para la defensa. El cerro se eleva a más de $200 \mathrm{~m}$ sobre el altiplano circundante. Para llegar al lugar se debe ascender por el lado oriental (Camacho, 1997: 55; Chambi Aguirre, 1997: 120). En la cima del cerro hay una pucara, un asentamiento fortificado con muros defensivos hechos de mampostería lítica tosca, además de corrales abandonados — posiblemente para camélidos_, más de 20 cimientos circulares de piedra (Ø 1-4 m), enterramientos cista y también chullpas de piedra en forma oval y cuadrangular (Palacios Alcoba, 1997: 8-9, 11, 15; Camacho, 1997: 55, 57, 60, 84-85; Chambi Aguirre, 1997: 121; Mendoza España, 1997: 152). Los tiestos recuperados en la superficie estaban decorados con motivos geométricos pintados en «negro sobre rojo» o «negro sobre amarillo-rojizo», y pueden ser clasificados también como tiestos Pacajes (Arellano Lopez et al., 1997).

En el lado suroeste de Pirapi Grande se encuentra el Cerro Pirapi Chico. No efectuamos investigaciones en ninguno de los cerros Pirapi, sino alrededor de una pequeña colina ubicada en el lado noreste de Estancia Lanquiri y justo frente al Cerro Pirapi Grande. Para evitar confusiones 
utilizaremos en adelante el nombre de Pirapi Chico como sinónimo para la colina. Pirapi Chico es muy pedregoso y fácil de localizar porque en su cima hay una fina chullpa de piedra de «estilo Cuzco» (8 m altura y forma redonda; fig. 8) En términos generales, durante nuestra visita en el sitio registramos 11 chullpas de piedra en un área aproximada de $0,5 \times 1,0 \mathrm{~km}$. De ellas, 10 son redondas y una es una chullpa de forma cuadrada (fig. 9). Más aún, hay una chullpa rectangular de adobe. Ocho chullpas están solas y cuatro chullpas forman dos pares. Curiosamente, en los aspectos tipológicos, las chullpas tienen contrapartes cercanas en la provincia de Lupaca (cf. Hyslop, 1977: fig. 6).

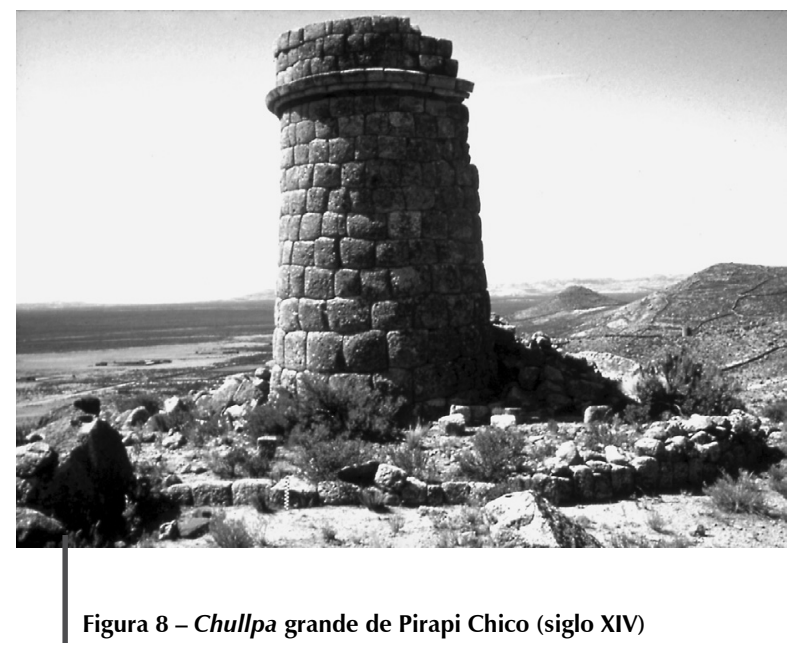

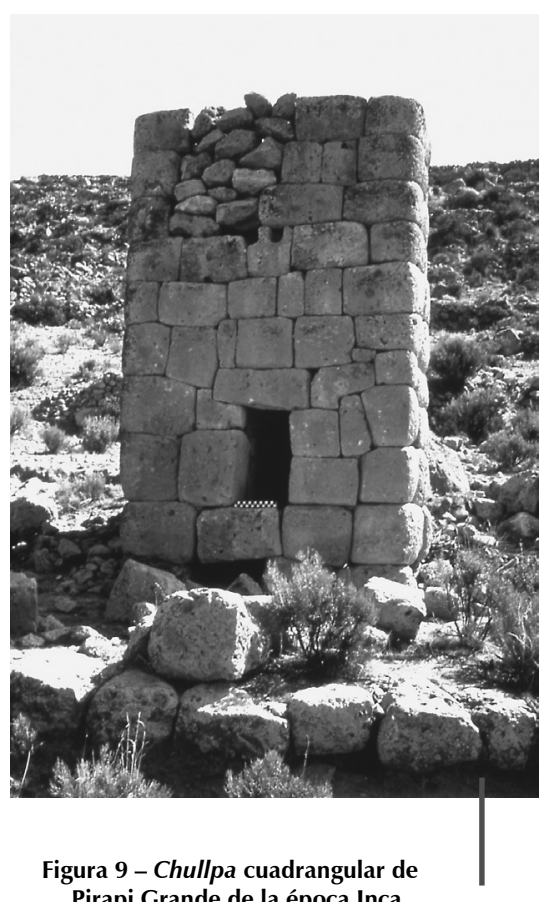

Pirapi Grande de la época Inca

Colectamos tres muestras radiocarbónicas de las chullpas de Pirapi. Dos fechas provienen de las chullpas de piedra en Cerro Pirapi Chico y una de la chullpa de adobe no lejos de las primeras. Tomamos la primera muestra en la pared de la cámara de estilo Cuzco de la chullpa redonda de piedra que está situada en la cima de Cerro Pirapi Chico. Es la chullpa más grande en el sitio (aprox. $8 \mathrm{~m}$ altura), inclinada y estrechándose en su parte superior. El diámetro de la base exterior es de 4,4 m. En su parte superior hay una cornisa de tres pasos hecha prolijamente. El interior de la chullpa consiste de un relleno de ripio y pequeños adoquines. La chullpa ha sido construida sobre una plataforma redonda que tiene $14 \mathrm{~m}$ de diámetro y $40-60 \mathrm{~cm}$ de altura. Hoy en día la chullpa está en malas condiciones porque el lado noreste ha colapsado parcialmente. Sin embargo, según Posnansky (1920: 57, citado por Camacho, 1997: 60), la torre tuvo originalmente «tres pisos, cada uno con su puerta». El vano rectangular, a nivel del suelo, está apuntando aproximadamente hacia el noreste, mientras que los otros dos vanos deben haber mirado hacia el este y NorEste-este, respectivamente. El diámetro de la cámara a nivel del suelo es de 2,4 m. La muestra radiocarbónica demuestra que la torre ha sido construida en el siglo XIV (Pärssinen, 2003: 230).

La segunda muestra fue tomada a la altura de 3,2 $\mathrm{m}$ en la chullpa cuadrangular de piedra tallada, situada a unos $100 \mathrm{~m}$ al sureste de la chullpa grande al pie de Cerro Pirapi Chico (cf. Posnansky, 1957: lámina c, d; Escalante, 1994: 431, fig. 366). En esta chullpa de cámara única la mampostería de piedra es de estilo Cuzco. En el lado este, frente al vano, hay una plataforma de piedra y en el lado oeste de la chullpa hay una terraza. La cámara es de 2,3 $\mathrm{m}$ de altura. Sobre el vano rectangular, a unos $2,5 \mathrm{~m}$ sobre el terreno, hay en la pared dos hoyos semicirculares paralelos, probablemente para la instalación de kerus de madera (cf. Arellano López, 2000: 23, foto 2). En el lado norte de esta chullpa hay una chullpa redonda de piedra cuya cornisa recuerda mucho a una chullpa en Cutimbo, Perú (cf. Hyslop, 1977: 153, fig. 4). En ambas chullpas 
el vano está apuntando hacia el este. La muestra de pasto (Ua-2905) extraída de la argamasa de la cámara sugiere que la torre rectangular fue construida entre 1436 y 1520 , es decir, en tiempos incas (Pärssinen, 2003: tabla 1; 2005: 155).

La tercera muestra fue tomada de la muy derruida y erosionada chullpa semi-rectangular de adobe (única de su tipo en el sitio), situada sobre una ladera ligeramente inclinada, a unos $200 \mathrm{~m}$ al noreste de la chullpa mayor en Pirapi Chico. En el lado norte de esta chullpa se encuentra una torre redonda de piedra cuya mampostería lítica es de estilo Cuzco. En estas chullpas los vanos también apuntan hacia el este. Las medidas exteriores de la chullpa de adobe son aproximadamente 3,5 x 2,5 m. Excepcionalmente, esta chullpa fue construida sobre una fina base de piedra al estilo Cuzco (Pärssinen, 2005: fig. 93; cf. también Escalante, 1994: 330, fig. 259). En el interior de la cámara se puede observar protuberancias de piedra en cada pared. La muestra de pasto (Ua-2906) obtenida de la pared de la cámara arrojó la fecha calibrada AD 1417 (1437) 1459, 1 sigma (Pärssinen, 2003: tabla 1; 2005: 155).

\section{5. Rosario}

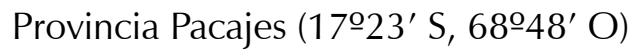

\section{5. 1. Chiarachullpa}

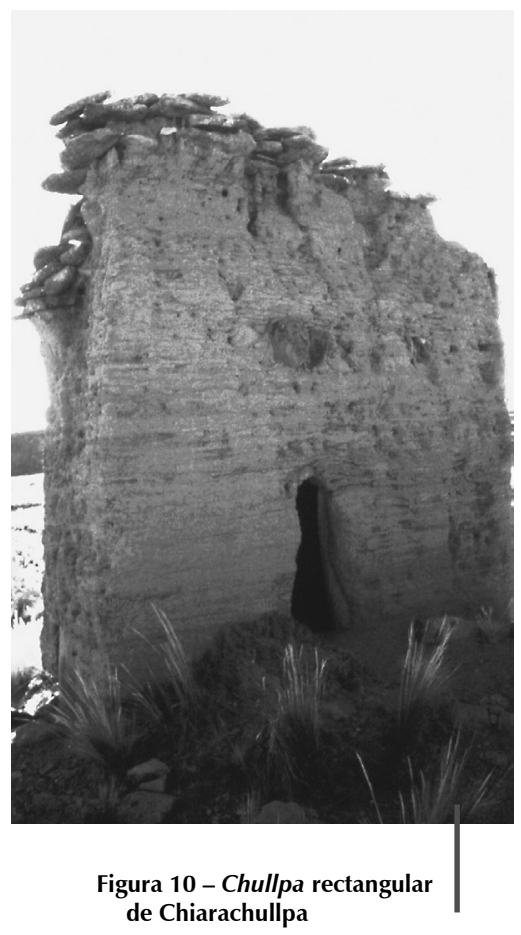

A unos $30 \mathrm{~km}$ al sureste de Achiri se encuentra el pueblo de Rosario, en cuyo alrededor se conocen varios chullpares. A unos $3 \mathrm{~km}$ al este de Rosario hay una necrópolis denominada Chiarachullpa, estudiada anteriormente por José Huidobro Bellido (1993: 57-87). En el año 2004 hicimos en este lugar algunas observaciones adicionales, principalmente en el sector central. Pese a que sólo 15 años atrás en este sector Huidobro había encontrado 47 torres, hoy en día ya no quedan sino los restos de unas 35 chullpas, además de algunas cistas subterráneas más pequeñas. Casi como regla general, todas estas chullpas tienen sus vanos orientados hacia el este. No obstante, la peculiaridad de las chullpas de Chiarachullpa radica en su construcción a base de adobes, aun cuando tienen un cimiento de varios machones altos de lajas (fig. 10). Además, como en algunas torres de Ch'usaqueri de Oruro, las chullpas tienen, a modo de techo, una corona de lajas y piedras naturales (cf. Huidobro Bellido 1993:62; Pärssinen 2005:156). Un detalle importante está en el promedio de sus proporciones que dan un valor índice de 0,85 lo que sugiere su pertenencia a la misma tradición rectangular de las chullpas de Sica Sica y de varias chullpas en Karanga y Sora.

Curiosamente, el sitio de Chiarachullpa parece haber formado un enclave particular en el área, puesto que otras chullpas de Rosario muestran generalmente algunas características similares con las chullpas de piedra de Achiri (Pakasa) y Kutimbo (área de Lupaca).

\section{5. 2. Jachaphasa}

Jachaphasa es una fortaleza situada a unos $2 \mathrm{~km}$ al noreste de Rosario. El interior de la fortaleza amurallada está compuesto por una meseta de unas 7 ha en forma de «Y〉》, orientada en dirección Oeste-Este. En la parte superior de varios edificios (la mayoría redondos) observamos en 2004 más 
de 100 chullpas de piedra, de forma redonda, concentradas en unos 10 ó 12 grupos. Entre estas chullpas hay también doce de forma cuadrangular, situadas mayoritariamente en sitios aislados fuera del área nuclear. Además, es importante notar que hay varias agrupaciones compuestas por una chullpa grande y otras 2-4 más pequeñas levantadas junto a la grande. Hay también tumbas en los aleros que son rocas erosionadas, e igualmente, observamos varias tumbas subterráneas en forma de cista cuadrangular ( $\varnothing \quad 45$ $50 \mathrm{~cm}$ ). La cerámica recolectada, generalmente bastante gruesa, es propia de los estilos Pacajes y «negro sobre rojo».

Para la datación radiocarbónica tomamos una muestra de paja de la argamasa de una chullpa de piedra tallada, forma cónica y base redonda (diámetro interior 175 $\mathrm{cm}$; altura exterior $390 \mathrm{~cm}$ ) (fig. 11). Según el análisis efectuado en el laboratorio Ångström de la Universidad de Uppsala, Suecia, la muestra identificada con el código Ua-23823 arroja la fecha $605 \pm 40$ (con la corrección equivalente ${ }{ }^{13} \mathrm{C}=-25 \%$ contra PDB). La fecha

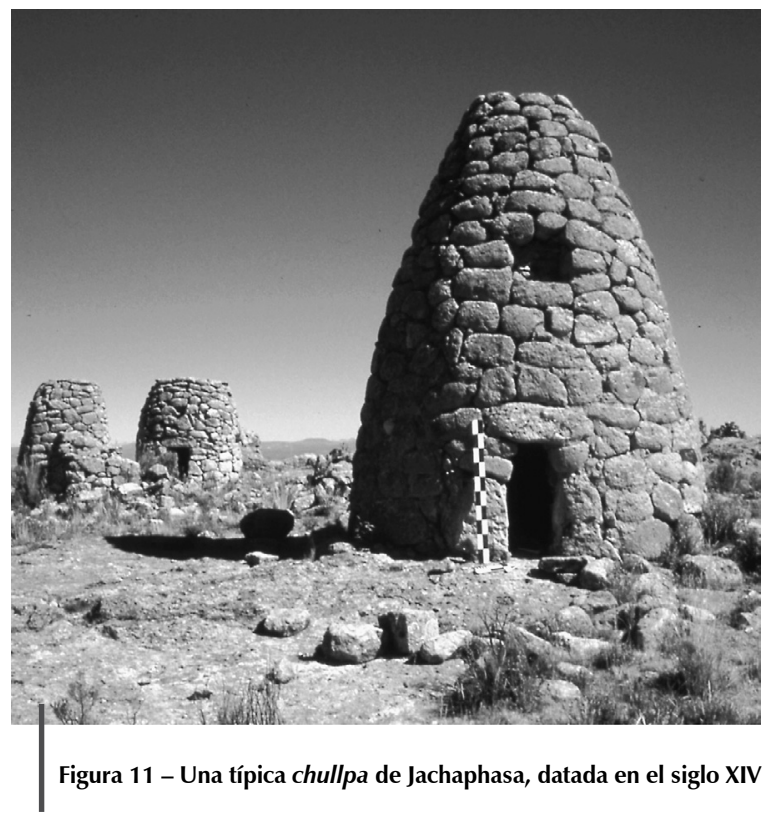

corresponde a los años calibrados 1323-1346 ó 1390-1418 (1 sigma, según Stuiver \& Reimer, 1993; McCormac et al., 2002: Calib Rev4.4). En base a este resultado, la fecha más probable de construcción de la chullpa es el siglo XIV.

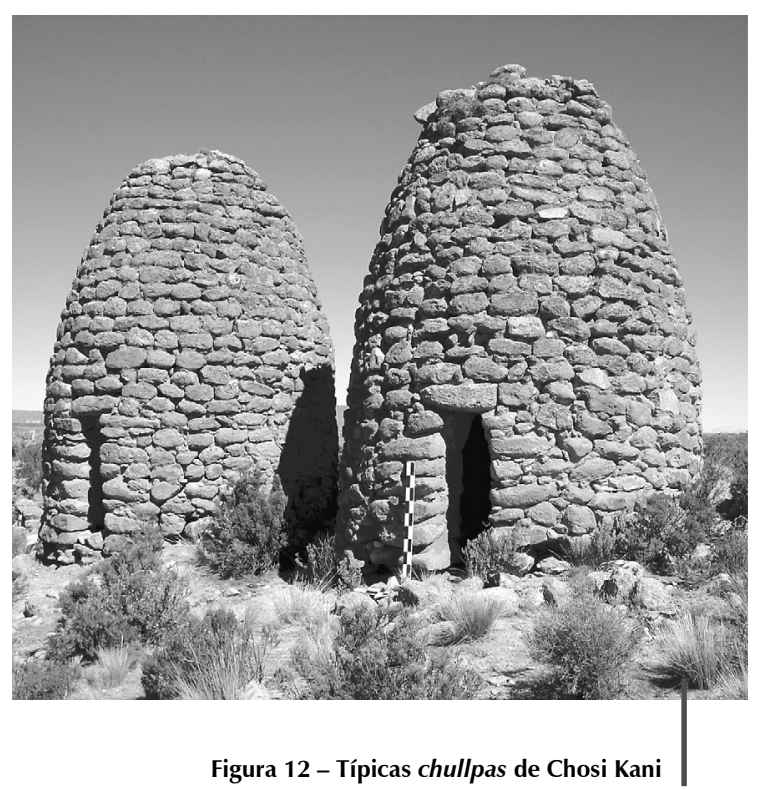

\section{6. Chosi Kani de Anantuco y Markiviri de Catacora}

Provincia Pacajes $\left(17^{\circ} 25^{\prime} \mathrm{S}\right.$, $\left.68^{\circ} 42^{\prime} \mathrm{O}\right)$

Continuamos nuestra prospección en el 2004 en la otra fortaleza denominada Chosi Kani, ubicada en el área del pueblo de Anantuco, unos $12 \mathrm{~km}$ al este de Rosario, en el otro lado del río Mauri. En general, Chosi Kani comparte características muy similares con Jachaphasa: está situada en la cima del cerro que forma una meseta amurallada con bases de casas redondas y una buena cantidad de chullpas y cistas observables. Según los datos de la expedición Kotamama, encima del cerro hay un total de 52 chullpas de piedra (Blashford-Snell \& Snailham, 2001). Al igual que en Jachaphasa, las chullpas tienen normalmente una forma cónica con 
base redonda (fig. 12). Además, en varias chullpas las osamentas estaban todavía casi intactas. Por ejemplo, en una chullpa calculamos 14 sacos de cestería donde los cadáveres con sus cráneos deformados conservaban la posición sedente. Había sacos para adultos ( $\varnothing$ aprox. 46 cm; altura $80 \mathrm{~cm}$ ), y sacos para niños (Ø $27 \mathrm{~cm}$; altura $40 \mathrm{~cm}$ ). La cerámica encontrada en la zona se parece

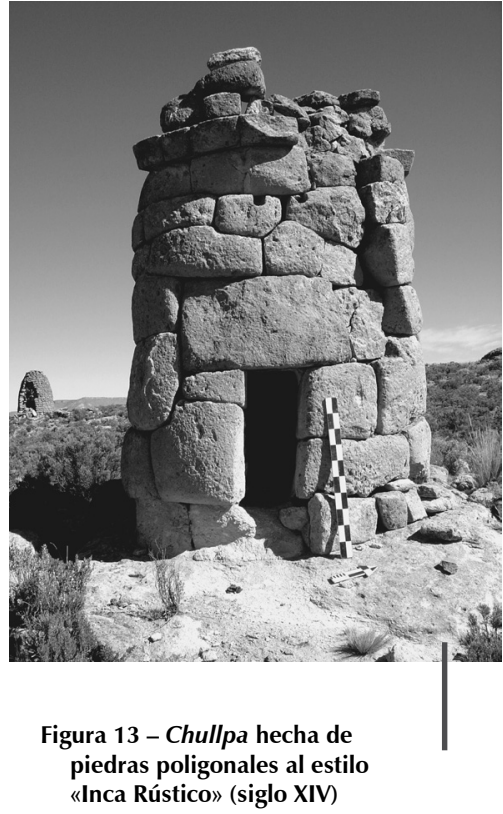
mucho a la de otras fortalezas de Pakasa (Achiri), Jachaphasa (Rosario), y Pucarpata (Caquiaviri) (cf. Pärssinen, 2005: 115117). Los fragmentos cerámicos, normalmente de platos y vasos pequeños, corresponden al estilo Pacajes y «negro sobre rojo».

Entre las chullpas de Chosi Kani hay dos torres que tienen características excepcionales. En el lado este se encuentra una chullpa redonda (Ø exterior $210 \mathrm{~cm}$; altura $350 \mathrm{~cm}$ ) hecha de piedras poligonales al estilo «Inca Rústico» (fig. 13). Arriba del vano $(90 \times 40 \mathrm{~cm})$ se encuentran dos huecos para los kerus de madera. Otra chullpa excepcional se encuentra aislada en el centro de la fortaleza. Se trata de una torre casi cuadrangular (altura 4,10 m; longitud $3 \mathrm{~m}$; ancho 2,65 m; índice 0,13, como las chullpas típicas de Caquiaviri). Además, en la pared norte exterior se ven rasgos de un dibujo geométrico hecho de barro color blanco, negro y rojo (fig. 14). En los capítulos siguientes trataremos más detalladamente sobre las chullpas decoradas y las chullpas «incaicas».

Después de la visita en el Cerro Chosi Kani nuestro equipo caminó con el guía unos $2 \mathrm{~km}$ al sureste, hacia el pueblo Catacora. Unos $500 \mathrm{~m}$ al este de la pequeña aldea y encima de una colina hay una chullpa de piedra redonda de grandes dimensiones $(\varnothing 5,5 \mathrm{~m}$; altura $8 \mathrm{~m}$ ) (fig. 15). Está bien conservada y a su lado se encuentra una chullpa cuadrangular de adobe. Ambas chullpas están construidas sobre una

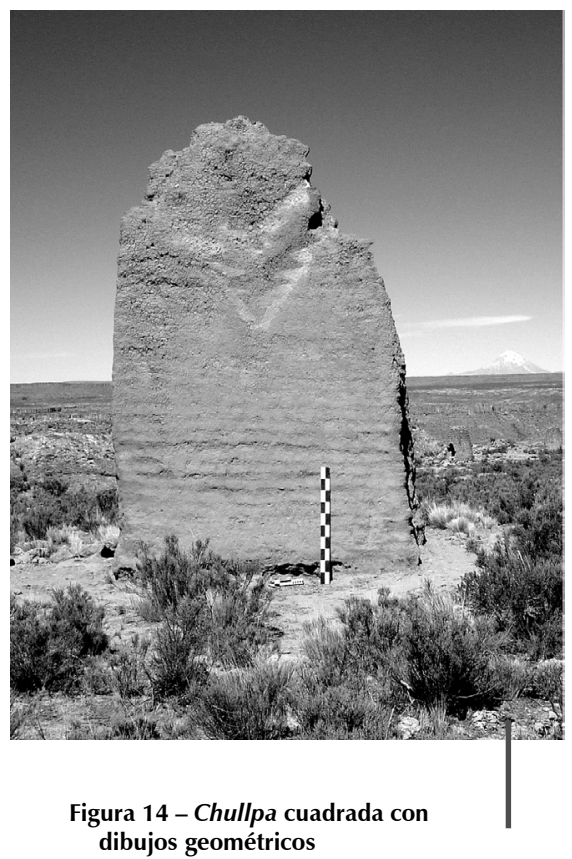

dibujos geométricos

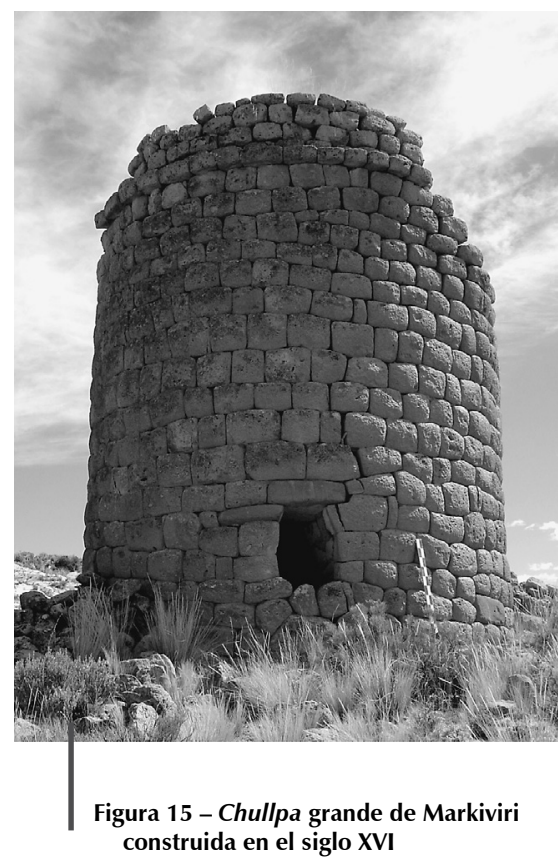

construida en el siglo XVI 
plataforma rectangular, lo que se puede apreciar especialmente en el lado este. Unos $20 \mathrm{~m}$ al sur del vano de la chullpa de piedra se encontró en el suelo el borde de un plato. Al limpiarlo y remover un poco más de tierra se descubrió un plato del estilo Inca-Pacajes con asa en forma de ave y diseños de llamitas. El plato estaba colocado como una tapa para cerrar la boca de una olla bastante gruesa. No pudimos determinar si la cerámica pertenecía a algún tipo de tumba, pues no había construcciones de piedra en las proximidades. Vale mencionar que $150 \mathrm{~m}$ al este de las chullpas, en el mismo sitio de Markiviri, hay un tambo incaico con dos kallankas: una bastante bien conservada $(37,25 \mathrm{~m} \times 8,45 \mathrm{~m})$ y la otra con signos de destrucción. Alrededor de estas kallankas hay muros de piedra, dos chullpas de piedra y por lo menos una chullpa de adobe.

En suma, la mayoría de los sitios descritos como Pirapi Chico (Achiri), Jachaphasa (Rosario) y Chosi Kani (Anantuco), son sitios defensivos. La cerámica pertenece al estilo Pacajes y a la tradición «negro sobre rojo» con algunas características más gruesas que la cerámica bien pulida llamada Inca-Pacajes, cuyo origen también parece ser preincaico (Pärssinen \& Siiriäinen, 1997). No obstante, la gran mayoría de las chullpas pertenece al estilo Lupaca, indicando fuertes vínculos étnicos con esta etnia. Además, la influencia Karanga $-\mathrm{y}$ posiblemente Sora- en las chullpas rectangulares de adobe parece acentuarse en el sitio de Chiarachullpa, pero en general, las pocas chullpas cuadrangulares de adobe que se encuentran en la zona pueden ser una influencia bastante tardía desde el núcleo de Pakasa.

\section{6. 1. Chullpas de tipo «Inca»}

En el altiplano boliviano hay varias chullpas con características del estilo «Inca». Ya hemos mencionado sitios como Pirapi Chico de Achiri, Chosi Kani de Anantuco, y Markiviri de Catacora en Pakasa. Igualmente, en Karanga hay varias chullpas con mampostería de piedras talladas: las observamos en el año 2004 en Jaraque, Antin Curahuara y Macaya; estos lugares son bien conocidos por los especialistas. No obstante, es importante destacar que las chullpas «incaicas» de Karanga tienen, como la mayoría de chullpas de adobe, una forma rectangular o semirectangular (índice 1 ó 0,5), mientras que las chullpas «incaicas» de Pakasa son redondas y cuadrangulares (índice 0).

Tal como uno de nosotros (MP) planteó anteriormente en referencia a la fecha obtenida de la chullpa grande (redonda) de piedra en Pirapi Chico (Achiri), es probable que el estilo arquitectónico conocido como Inca estuviera ya presente en el altiplano boliviano desde casi un siglo antes de la conquista cuzqueña (Pärssinen, 1993; 2003; 2005). Además, no se debe descartar que los arquitectos incas adaptaran el estilo del área del Titicaca, debido a que varias fuentes confirman la utilización de albañiles lupacas y pakasas en las construcciones del Cuzco (Cieza de León, 1986 [1553]: 284; Sarmiento, 1943 [1572]: 199; Díez de San Miguel, 1964 [1567]: 39, 80, 92, 106, 116, 204; Cabeza de Vaca, 1885 [1586]: 71; Cobo, 1964 [1653]: 82; cf. también Gasparini \& Margolies, 1980: 11; Murra, 1988: 72; Isbell, 2001: 323). Dado que los incas del Cuzco preferían las formas cuadrangulares y rectangulares, y como la chullpa cuadrangular de «tipo Inca» de Pirapi Chico data del Horizonte-Tardío, decidimos verificar si en realidad todas las chullpas redondas de estilo «Inca» eran o no preincaicas. Para ello, procedimos a la datación de la chullpa redonda de piedras poligonales al estilo «Inca Rústico» (Chosi Kani de Anantuco), así como de la chullpa grande de Markiviri (Catacora). La primera muestra (Ua23824) da la fecha AP 595 \pm 50 , demostrando que pertenece a la misma época que la chullpa cercana de Jachaphasa, es decir, al siglo XIV o las primeras décadas del siglo XV (1323-1346 ó 1390-1428 d. C., según la probabilidad de 1 sigma de Stuiver \& Reimer, 1993 y McCormac et al., 2002: Calib Rev4.4). La fecha apoya nuestra hipótesis de que el estilo se originó en el altiplano boliviano ya en tiempos preincaicos. No obstante, la chullpa grande de Markiviri, situada al lado del tambo incaico, da la fecha AP 305 \pm 40 que corresponde a los años calibrados AD 1510-1551, 1559-1575, 1622-1654 ó 1658-1666 (1 sigma). Esto significa que la tradición de construir chullpas de piedras talladas «tipo Inca» continuó hasta finales de la época Inca e incluso hasta inicios de la época Colonial. 
De todos modos, según nuestras evidencias actualizadas, las chullpas redondas del tipo «Inca» tienen, de hecho, un origen preincaico en Pakasa, mientras que las chullpas rectangulares y cuadrangulares de tipo «Inca» serían innovaciones del Horizonte-Tardío. Además, ambas variantes siguieron estando en uso hasta la época de la Conquista española.

\section{6. 2. Chullpas decoradas}

Como hemos señalado anteriormente, en Caquiaviri hay algunas chullpas decoradas mediante adobes de diferentes colores. Por otro lado, en Chosi Kani observamos una chullpa decorada utilizando barro coloreado para «pegar» un dibujo geométrico sobre el revestimiento o revoque. En el valle Ollachea (norte de La Paz), así como en el norte de Chile, se conocen también algunas chullpas con revestimiento coloreado (Nordenskiöld, 1953: 69-77, Lam. 4; 2c, 3c; Squier, 1973 [1877]: 131; Daulsberg, 1983: 73; Muñoz Ovalle, 1998: 131). Igualmente, en Kuntur Amaya y en Mallku Chullpa (sur de Pakasa), se conocen chullpas revestidas con barro y chullpas decoradas por composición de adobes, respectivamente (Sagárnaga Meneses, 1997: 30-31; Kesseli et al., 1999: 347). No obstante, la posición de esas chullpas no está claramente en el núcleo de las grandes agrupaciones de torres, y la impresión general es que estas chullpas nunca constituyeron una mayoría entre las chullpas del altiplano.

De hecho, solamente en algunos sitios de Karanga tenemos una mayor concentración de chullpas decoradas. Más conocidas son las chullpas rectangulares de Macaya y Sacabaya en el área del río Lauca, estudiadas por Teresa Gisbert y sus colegas (Gisbert et al., 1994; Gisbert, 1999). En la decoración se utilizaron tanto la técnica de revestimiento como la de adobes coloreados. Además, la cerámica recolectada incluye tiestos Karangas (Chilpe), Inca e Inca-Pacajes (observación propia en 2004). Durante las prospecciones de Karanga encontramos también un sitio cerca de Estancia Mamanjalla, a 2,5 km al este de Crucero, donde observamos los restos de nueve chullpas. De éstas, había tres decoradas con la composición geométrica de adobes coloreados (gris claro, gris oscuro, negro y rojo). Igualmente, todas estas chullpas tienen forma rectangular como la gran mayoría de chullpas de Karanga. Además, alrededor de las chullpas de Mamanjalla recolectamos también varios tiestos Inca, Inca-Pacajes, Karangas (Chilpe) y algunos tiestos con ganchos pintados, reminiscentes del estilo Caquiaviri (cf. Pärssinen, 2005: 204).

Tal como uno de nosotros (Pärssinen, 1993: 16; cf. también Gisbert et al., 1994) había anotado anteriormente, las figuras geométricas en las chullpas parecen tener una conexión con los textiles y motivos cerámicos incaicos (cf. por ejemplo fig.1.3.2 en Pärssinen, 1993 y Túnica

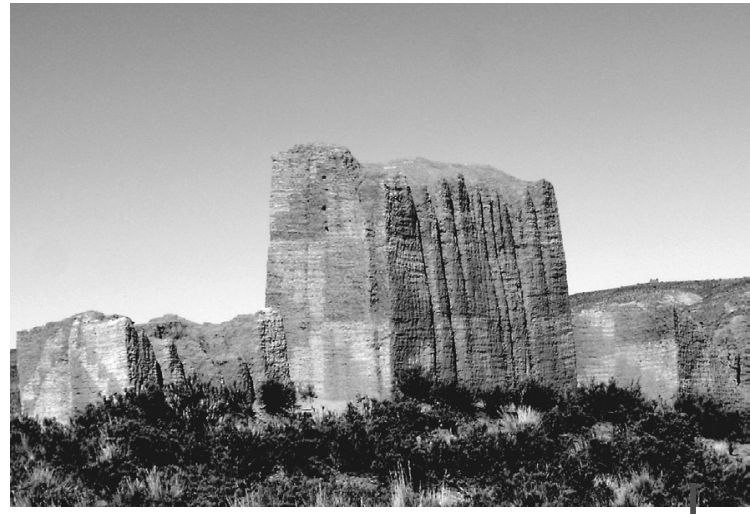

Figura 16 - Chullpas decoradas de Mamanjalla en Crucero

La chullpa grande data del siglo XVI

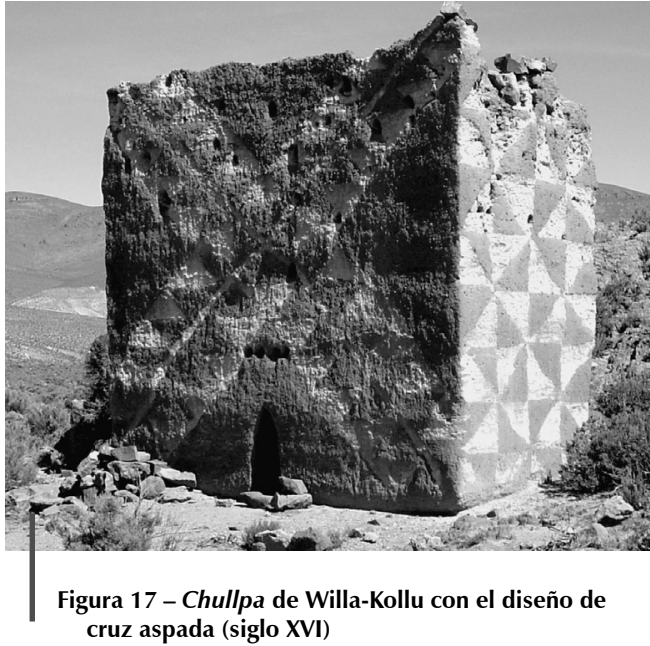

cruz aspada (siglo XVI) 
de Caudeville publicado por Morris \& von Hagen, 1993: fig. 184; cf. también Gallardo, 1993: fig. 15). También el hallazgo de cerámica Inca e Inca-Pacajes en muchos de los sitios con chullpas decoradas, indica que éstas pertenecen al período Inca. Sin embargo, es importante notar que muchos de aquellos motivos, aunque adaptados por los incas, eran de uso general ya en el período Intermedio-Tardío (cf. Pärssinen \& Siiriäinen, 1997: 255-271). Este es el porque decidimos obtener evidencia independiente sobre la edad de las chullpas decoradas. En este sentido, en Mamanjalla tomamos una muestra de la chullpa más grande decorada con un diseño «diamante» (fig. 16); en Sacabaya tomamos muestras de tres chullpas: una de Willa-Kollu (chullpa con el diseño de cruz aspada; fig. 17), y dos de Churi-Patilla (T13 y T8, según Gisbert, 1999). Los resultados de la prueba sugieren que las chullpas de Mamanjalla y Willa-Kollu pertenecen al siglo XVI (calibrado 1 sigma), mientras que las dos chullpas de Churi-Patilla pueden ser datadas en la segunda mitad del siglo XV (1 sigma, según Stuiver \& Reimer, 1993 y McCormac et al., 2002: Calib Rev4.4). Esto sugiere que todas las chullpas con decoración geométrica de Karanga que fueron datadas pertenecerían realmente al período Inca. Al emplear analogía, asumimos que también las chullpas decoradas en Pakasa son del mismo período.

\section{CONCLUSIONES}

En este artículo hemos tratado distintas tradiciones de construir chullpas dentro del área histórica de Pakasa (fig. 18). Además, hemos demostrado que el estilo de mampostería incaica en las chullpas puede tener sus raíces en el área suroeste de Pakasa o bien en Lupaca. Esto se hace evidente especialmente en las chullpas redondas, pues sus construcciones se iniciaron ya en el siglo XIV, mientras las chullpas cuadrangulares y rectangulares del mismo estilo arquitectónico parecen haber sido una adaptación aplicada durante el Horizonte-Tardío. Igualmente, las chullpas decoradas parecen haber sido construidas básicamente durante la época Inca.

Si aceptamos la tesis de que las costumbres funerarias reflejan los sentimientos y la cosmovisión fundamental de una etnia, entonces podemos plantear, como hipótesis, que las distintas tradiciones mencionadas reflejan diferencias étnicas dentro del antiguo señorío de Pakasa. Especialmente, la orientación hacia tres direcciones cardinales de las chullpas en las orillas e islas de Lago Titicaca (Qiwaya, Taramaya, Taquiri) y en Charazani, parece tan fundamental,

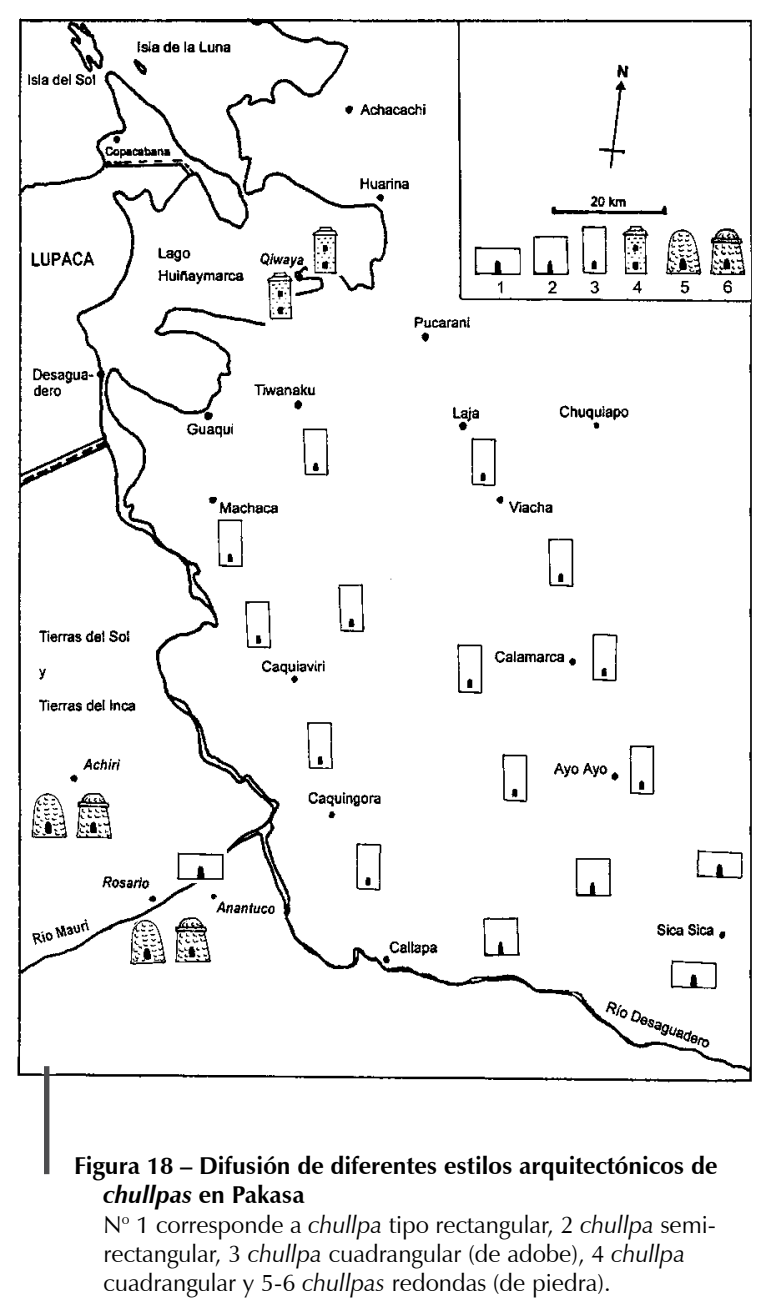


que es necesario plantear la posibilidad de que fueran construidas por los puquina, y no por los aymara. Como explican las fuentes históricas, en dichas áreas el puquina fue un idioma común durante la época Colonial. Además, aunque en Qiwaya y Taramaya la cerámica parece ser una variante de Pakasa (Umasuyu), toda la parte este del Titicaca pertenece ya a la tradición cerámica Mollo, que puede ser interpretada como un reflejo de la misma realidad étnica.

En otras áreas Pakasa la orientación de las chullpas es siempre hacia el este, con pequeñas variaciones casuales. No obstante, hay una gran diferenciación entre las chullpas de piedra con base redonda (suroeste de Pakasa) y las chullpas cuadrangulares (núcleo de Pakasa) y las chullpas rectangulares (sur y sureste de Pakasa). Las chullpas de piedra con base redonda están claramente relacionadas con las chullpas del área Lupaca, mientras que las chullpas rectangulares y también semi-rectangulares que se conocen en el sur de Pakasa (Ponce Sanginés, 1958; 1959; 1993; Sagárnaga Meneses, 1997) pertenecen a la tradición compartida con los karanga y sora en ambos lados del Lago Poopó. Por ello, parece probable que todavía en el siglo XIV, cuando la tradición chullparia se generalizaba repentinamente, el señorío de Pakasa no fuera tan uniforme como describen los documentos de la época de Conquista española. No obstante, no sabemos si las áreas periféricas de Pakasa, desde el punto de vista de Caquiaviri y del núcleo de Pakasa, fueron integradas bajo Caquiaviri, capital de Pakasa, ya antes de la conquista incaica o, si en realidad, fue una formación incaica del siglo XV.

De todos modos, con este artículo hemos querido demostrar que existe en realidad una fuerte correspondencia entre los estilos arquitectónicos de torres funerarias y los territorios de ciertos grupos étnicos en el altiplano boliviano prehispánico. Estas evidencias pueden tener consecuencias significativas, también, para el debate teórico sobre la correspondencia entre la identidad étnica y la cultura material (cf. Browman, 1994; Jones, 2000; Lecoq, 1997; Pärssinen, 1997) Por ello, estas chullpas son importantes testimonios del pasado, especialmente de las épocas que van desde el Intermedio-Tardío hasta el Colonial-Temprano en los Andes Centro Sur. Además, forman parte del paisaje cultural y las podemos calificar como patrimonio nacional y transnacional, e incluso mundial. Por todo ello, las chullpas merecen medidas urgentes de protección. Si no las protegemos hoy, la mayoría de ellas desaparecerá dentro de los próximos 50 años.

\section{Agradecimientos}

Agradecemos a la Academia de Finlandia, la Dirección Nacional de Arqueología de Bolivia, la Universidad de Helsinki y el CEISAL y a sus respectivos directores, el apoyo dado para llevar a cabo los proyectos arqueológicos de «Caquiaviri», «Chullpa Pacha» y «Formaciones y Transformaciones de las Identidades Etnicas en los Andes Centro Sur, 700-1825 d. C.». Queremos agradecer también la colaboración de Juan Faldín, Jedú Sagárnaga y Antti Korpisaari, codirectores de unos proyectos y la de Julio César Velásquez, director de Museo Nacional de Arqueología de Bolivia. También a Reino Kero y a Ari Siiriäinen (+), directores de unos fases de esos proyectos, aparecen en este agradecimiento con todo derecho. Finalmente agradecemos a Heli Pärssinen, Ilse-Mari Söderholm, Kreetta Lesell, Marjut Jalkanen-Mäkelä, Petri Liuha, Matti J. Rossi, Jonny Bustamante, Danilo Villamor, Ruden Plaza Martínez y Victor Plaza Martínez, con quien hemos trabajado en el campo, como también a los numerosos colegas y amigos en Bolivia, Finlandia, y otros países que nos han brindado apoyo para llevar a cabo la investigación. 


\section{Referencias citadas}

ABBOTT, M. B., BINFORD, M. W., BRENNER, M. \& KELTS, K. R., 1997 - A 3500 14C yr HighResolution Record of Water-Level Changes in Lake Titicaca, Bolivia/Peru. Quaternary Research, 47: 169-180.

ABERCROMBIE, T. A., 1998 - Pathway of Memory and Power, Ethnography and History among an Andean People, 603 p.; Madison: University of Wisconsin Press.

ADELAAR, F. H., 1987 - Comentarios. Revista Andina 5 (2): 373-375.

ALBARRACíN-JORDÁN, J., 1996 - Tiwanaku. Arqueología regional y dinámica segmentaria, 393 p.; La Paz: CID Plural - Publicidad Arte Producciones.

ALBARRACíN-JORDÁN, J., 1999 - The Archaeology of Tiwanaku. The Myths, History, and Science of an Ancient Andean Civilization, 105 p.; La Paz: Impresión P. A. P.

ALDUNATE DEL SOLAR, C., BERENGUER, J. \& CASTRO ROJAS, V., 1982 - Las funciones de las chullpa en Likan. In: Actas del VIII Congreso de Arqueología Chilena: 129-174; Valdivia: Kultrun Ltda. Valdivia, 10 al 13 de octubre de 1979.

ALDUNATE DEL SOLAR, C. \& CASTRO ROJAS, V., 1981 - Las chullpa de Toconce y su relación con el poblamiento Altiplánico en el Loa Superior Periodo Tardío, 206 p. Tesis, Universidad de Chile, Santiago.

ÁLVAREZ, B., 1998 [1588] - De las costumbres y conversión de los indios del Perú: Memorial a Felipe II, 462 p.; Madrid: Ediciones Polifemo, Crónicas y Memorias 4.

ARELLANO LÓPEZ, J., 2000 - Arqueología de Lipes: Altiplano sur de Bolivia, 284 p.; Quito: Museo Jacinto Jijón y Caamaño - PUCE - Taracacum Washington D. C.

ARELLANO LÓPEZ, J. \& BERBERIÁN, E. E., 1981 - Mallku, el señorío post-Tiwanaku del altiplano sur de Bolivia. Bulletin de I'Institut Français d'Études Andines, 10 (1-2): 51-84.

ARELLANO LÓPEZ, J., PALACIOS A. G., CAMACHO T. L., CHAMBI A. J., MENDOZA E. V., YAÑEZ, V. R. \& GUTIERREZ O. D., 1997 - Informe Final: Proyecto arcaico-formativo en el altiplano del Departamento de La Paz/Investigaciones arqueológicas en el Cantón Achiri de la provincia Pacajes, 262 p.; La Paz: Universidad Mayor de San Andrés, carrera de antropología y arqueología. Ms.

AYCA GALLEGOS, O., 1995 - Sillustani, 164 p.; Tacna: Instituto de Arqueología del Sur.

BANDELIER, A. F., 1910 - The islands of Titicaca and Koati, 358 p.; New York: The Hispanic Society of America.

BENGTSSON, L., 1998 - Prehistoric Stonework in the Peruvian Andes. A case Study at Ollantaytambo, 220 p.; Goteborg: Göteborg University, department of Archaeology \& Etnografiska museet. GOTARC Series B, $\mathrm{n}^{\circ} 10$ \& Etnologiska studier 44.

BENNETT, W. C., 1950 - Cultural unity and disunity in the Titicaca Basin. American Antiquity, 16 (2): 89-98.

BERENGUER, J., ALDUNATE, C. \& CASTRO, V., 1984 - Orientación orográfica de las chullpas en Likan: la importancia de los cerros en la fase Toconce. In: Simposio Culturas Atacameñas. 44 Congreso Internacional de Americanistas: 175-220; Chile: Universidad del Norte.

BERNEDO MALAGA, L., 1949 - La cultura puquina o prehistoria de la provincia de Arequipa, 144 p.; Lima: Ministerio de Educación Pública.

BERTONIO, L., 1984 [1612] - Vocabulario de la lengua aymara, 399 p.; Cochabamba: Ediciones Ceres.

BINFORD, M. \& KOLATA, A., 1996 - The Natural and Human Setting. In: Tiwanaku and Its Hinterland: Archaeology and Paleoecology of an Andean Civilization: 23-56; Washington, D. C.: Smithsonian Institution Press.

BINFORD, M. W., BRENNER, M. \& ENGSTROM, D. R., 1991 - Patrones de sedimentación temporal en la zona litoral del Huiñaimarca. In: El lago Titicaca: 47-57; La Paz: ORSTOMHisbol. 
BLASHFORD-SNELL, J. \& SNAILHAM, R., 2001 - Kota Mama. From the Andes to the Atlantic-an Amazing Journey of Adventure and Discovery, 287 p.; Headline Book Publishing Ltd.

BOUYSSE-CASSAGNE, T., 1975 - Pertenencia Etnica, Status Económico y Lenguas en Charcas a fines del Siglo XVI. In: Tasa de la visita general de Francisco de Toledo: 312-328; Lima: Universidad Nacional Mayor de San Marcos.

BOUYSSE-CASSAGNE, T., 1986 - Urco and Uma: Aymara concepts of space. In: Anthropological History of Andean Polities: 201-227; Cambridge: Cambridge University Press.

BOUYSSE-CASSAGNE, T., 1987 - La identidad Aymara. Aproximación histórica (siglo XV, siglo XVI), 433 p.; La Paz: Biblioteca Andina, serie histórica, Hisbol.

BROWMAN, D. L., 1994 - Titicaca Basin archaeolinguistics: Uru, Pukina and Aymara AD 7501450. World Archaeology, 26 (2):235-251.

BUSTAMANTE, J., 1998 - De labores desarrolladas en la localidad de Qiwaya en el marco del proyecto Chullpa Pacha '98, 96 p; La Paz. Informe inédito presentado a la Dirección Nacional de Arqueología y Antropología.

CABEZA DE VACA, D., 1885 [1586] - Descripción y relación de la ciudad de La Paz. In: Relaciones Geográficas de Indias, t. II: 65-80; Madrid: Ministerio de Fomento.

CAMACHO, T. L., 1997 - Aspectos generales del trabajo de investigación en la región de Achiri. In: Informe inédito final. Proyecto arcaico-formativo en el altiplano del departamento de La Paz - Investigaciones arqueológicas en el Cantón Achiri de la provincia Pacajes: 54-61; La Paz: Universidad Mayor de San Andrés, carrera de antropología y arqueología.

CASANA ROBLES, T., 1976 - Restos Arqueológicos de la Provincia de Canta y de la Provincia de Huaral, 238 p.; Lima: Colegio Militar.

CHAMPI AGUIRRE, J., 1997 - Investigaciones arqueológicas en Achiri. In: Informe final. Proyecto arcaico-formativo en el altiplano del Departamento de La Paz - Investigaciones arqueológicas en el Cantón Achiri de la provincia Pacajes: 118-139; La Paz: Universidad Mayor de San Andrés, carrera de antropología y arqueología. Ms.

CIEZA DE LEÓN, P. de, 1986 [1553] - Crónica del Perú. Primera parte, 353 p.; Lima: Pontificia Universidad Católica del Perú (segunda edición corregida).

COBO, B., 1964 [1653] - Historia del Nuevo Mundo, t. II, Biblioteca de Autores Españoles, t. XCII, 515 p.; Madrid: Ediciones Atlas.

CONDARCO MORALES, R., 1985 - Atlas histórico de Bolivia, 65 p.; La Paz: Editorial «San José».

CONDARCO MORALES, R., 1993 - Oruro Arqueológico (mapa). In: HOY, suplemento Pumapunku, cuarta semana de mayo: 2; La Paz.

DEL RÍO, M., 1998 - Ancestros, guerras y migraciones. Reflexiones en torno al origen y vinculaciones étnicas de los Soras de la provincia de Paria. Historias... Revista de la Coordinadora de Historia, 2: 93-112; La Paz. Número especial en homenaje a Teresa Gisbert.

DAUELSBERG, P., 1983 - Investigaciones arqueológicas en la Sierra de Arica, sector Belén. Chungará, 11: 63-83.

DÍEZ DE SAN MIGUEL, G., 1964 [1567] - Visita hecha a la provincia de Chuchito, 445 p.; Lima: Casa de la Cultura.

DILLEHAY, T. D., 1995 - Introduction. In: Tombs for the Living: Andean Mortuary Practices: 1-26; Washington, D. C.: Dumbarton Oaks Research Library and Collection.

D'ORBIGNY, A., 1958 [1839] - Viaje a la América meridional, 4 vols., 1120 p.; Madrid: Bibliotheca Indiana. Aquilar.

ESCALANTE MOSCOSO, J., 1994 - Arquitectura prehispánica en los Andes bolivianos, 507 p.; La Paz: Producciones CIMA.

ESCOBARI DE QUAREJAZU, L., 1983 - La heraldica incaica y los caciques Cusicanqui de Pacajes. Arte y Arqueología, 8-9:163-166; La Paz. 
FLORES APAZA, P., MONTES, F., ANDIA, E. \& HUANACUNI, F., 1999 - El hombre que volvió a nacer: vida, saberes y reflexiones de un amawt'a de Tiwanaku, 224 p.; La Paz: Plural editors - CID - Universidad de Cordillera.

FORBES, D., 1870 - On the Aymara Indians of Bolivia and Peru. The Journal of the Ethnological Society of London, 2: 193-305.

GALLARDO, F., 1993 - La sustancia privilegiada: Turbantes, poder y simbolismo en el Formativo del norte de Chile. In: Identidad y prestigio en los Andes. Gorros, turbantes y diademas: 9-15; Santiago: Museo Chileno de Arte Precolombino.

GARCILASO DE LA VEGA, I., 1976 [1609] - Comentarios reales de los Incas, t. I-II, 593 p.; Venezuela: Biblioteca Ayacucho, Italgráfica S. R. L.

GASPARINI, G. \& MARGOLIES, L., 1980 - Inca Architecture, 350 p.; Bloomington: Indiana University Press.

GIL GARCíA, F., 2000 - Manejo simbólico del espacio andino y estructuras chullparias: propuestas interpretativas, 287 p. Tesis de Licenciatura. Universidad Complutense de Madrid, Facultad de Geografía e Historia, Dpto. de Historia de América II (Antropología de América).

GIL GARCíA, F., 2001 - Ideología, poder, territorio. Por un análisis del fenómeno chullpario desde la arqueología de la percepción. Revista Española de Antropología Americana, 31: 59-96.

GIL GARCÍA, F., 2002 - Acontecimientos y regularidades chullparias. Más allá de las tipologías: reflexiones en torno a la construcción de un paisaje chullpario. Revista Española de Antropología Americana, 32: 207-241.

GISBERT DE MESA, T., 1987- Los cronistas y las migraciones aimaras. Historia y Cultura, 12: 1-10; La Paz.

GISBERT DE MESA, T., 1999 - El paraíso de los pájaros parlantes. La imagen del otro en la cultura andina, 316 p.; La Paz: Plural Editores, Universidad Nuestra Señora de La Paz.

GISBERT DE MESA, T., 2000 - Les nécropoles des hauts plateaux. Archéologia, 363: 42-47; Dijon.

GISBERT, T., JEMIO, J. C. \& MONTERO, R., 1994 - El señorío de los Carangas y los chullpares del Río Lauca. Revista Andina, 12 (2): 427-485.

GUERRA GUTIERREZ, L., 1982 - Mapa e inventariación de los yacimientos arqueológicos de Oruro, 21 p.; La Paz. Informe inédito para el Instituto Nacional de Arqueología de Bolivia.

HARRIS, O., 1983 - Los muertos y los diablos entre los Laymi de Bolivia. Chungará, 11: 135152; Arica.

HEREDIA ZAVALA, M. A., 1990 - Arqueología para Culli Culli. Textos Antropológicos, 1: 119122; La Paz.

HeReDiA ZAVALA, M. A., 1991 - Arqueología para Culli Culli: Primeros resultados. Textos Antropológicos, 2: 97-114.

HeREDiA ZAVALA, M. A., 1993 - Las torres funerarias de Kullikulli. Pumapunku, Nueva Época, 5-6: 163-171; La Paz.

HERRMANN, B. \& MEYER R. D., 1993 - Sudamerikanische mumien aus vorspanischer zeit. Eine radiologische untersuchung, 134 p.; Berlin: Veröffentlichungen des Museums fur Völkerkunde, Neue Folge 58. Staatliche Museum zu Berlin-Preusischer Kulturbesitz.

HUIDOBRO BELLIDO, J., 1993 - Arqueología funeraria del señorío aymara Pakasa (posTiwanaku). Pumapunku, Nueva Época, 5-6: 57-87.

HYSLOP, J., 1976 - An archaeological investigation of the Lupaca Kingdom and its origins, 449 p.; Dissertation in the Columbia University, Ann Arbor, Michigan: Xerox University Microfilms.

HYSLOP, J., 1977 - Chulpas of the Lupaca Zone of the Peruvian High Plateau. Journal of Field Archaeology, 4 (2): 149-170. 
IBARRA GRASSO, D. \& QUEREJAZU LEWIS, R., 1986 - 30000 años de prehistoria en Bolivia, 365 p.; La Paz - Cochabamba: Editorial Los Amigos del Libro.

ISBELL, W. H., 1997 - Mummies and Mortuary Monuments. A Postprocessual Prehistory of Central Andean Social Organization, 371 p.; Austin: University of Texas Press.

ISBELL, W. H., 2001 - Huari: An Imperial Capital. In: Gold crown and feather mantle. The Incas and their predecessors - Three millennia of Pre-Columbian Peru: 320-324; Tampere: Tampere Art Museum publication 94.

JONES, S., 2000 - Discourses of Identity in the Interpretation of the Past. In: Interpretive Archaeology: A Reader: 445-457; London - New York: Leicester University Press.

KAULICKE, P., 2001 - Memoria y muerte en el Perú antiguo, 387 p.; Lima: Pontificia Universidad Católica del Perú.

KESSELI, R., 2001 - The Grave Towers of the Bolivian High Plateau. In: Gold crown and feather mantle. The Incas and their predecessors - Three millennia of Pre-Columbian Peru: 352355; Tampere: Tampere Art Museum publication 94.

KESSELI, R., LIUHA, P., ROSSI, M. \& BUSTAMANTE, J., 1999 - Archaeological and Geographical research of Precolumbian (AD 1200-1532). Grave Towers or Chullpa on the Bolivian High Plateau in the Years 1989-1998. Preliminary report. In: Dig it all: Papers dedicated to Ari Siiriäinen: 335-348; Helsinki: The Finnish Antiquarian Society, The Archaeological Society of Finland.

KESSELI, R., SAGÁRNAGA MENESES, J., KORPISAARI, A. \& BUSTAMANTE, J., 2003 - Informe sobre las investigaciones arqueológicas realizadas en torres funerarias de piedra de Taramaya, Provincia Los Andes, agosto 2002. In: Reports of the Finnish-Bolivian Archaeological Project in the Bolivian Amazon II: 97-120; Helsinki: Department of Archaeology, University of Helsinki.

KOLATA, A. L., 1993 - The Tiwanaku. Portrait of an Andean Civilization. The Peoples of America, 317 p.; Cambridge, Massachusetts: Blackwell Publishers.

KORPISAARI, A., 2000 - Proyecto Chullpa Pacha '98: La limpieza de la cámara inferior de la chullpa de piedra C-17 de Qiwaya, 10 p.; La Paz: Informe inédito presentado a la Dirección Nacional de Arqueología y Antropología (DINAAR).

KORPISAARI, A. \& PÄRSSINEN, M. (ed.), 2005 - Pariti: isla, misterio y poder. El tesoro cerámico de la cultura Tiwanaku, 80 p.; La Paz: Viceministerio de Cultura - República de Bolivia.

LARTAN, E. de, 1980 [1608] - Relación de la provincia de los Pacajes que se a hecho y averiguado en virtud de una carta que los senores de la real audiencia de la ciudad de la plata embiaron a don estevan de lartan corregidor de ella. In: Historiografía y Bibliografía Americanistas XXIV:12-21.

LE GOFF, J., 1995 - Histoire et mémoire, 409 p.: Gallimard, Collection Folio/Histoire.

LECOQ, P., 1991 - Sel et archéologie en Bolivie. De quelques problèmes relatifs à l'occupation préhispanique de la cordillère Intersalar (Sud-Ouest Bolivien), 443 p. Thesis doctoral, Universidad de Paris 1, Panthén-Sorbonne, Microfiche 0745.12393/92, A. N. R. T. Université de Lille III.

LECOQ, P., 1997 - Patrón de asentamiento, estilos cerámicos y grupos étnicos: el ejemplo de la región Intersalar en Bolivia. In: Saberes y Memorias en los Andes. In Memoriam Thierry Saignes: 59-89; Paris - Lima: Institut des Hautes Études de l'Amérique Latine - Institut Français d'Études Andines.

LUMBRERAS, L.G. \& AMAT, H., 1968 - Secuencia arqueológica del Altiplano Occidental del Titicaca. In: Actas del XXXVII Congreso Internacional de Americanistas, vol. II: 75-106; Buenos Aires.

MCCORMAC, F., REIMER, P., HOGG, A., HIGHAM, T., BAILLIE, M., PALMER, J. \& STUIVER, M., 2002 - Calibration of the radiocarbon time scale for the southern hemisphere AD 1850950. Radiocarbon, 44: 641-651. 
MEJÍA XESSPE, T., 1979 - Cultura Pukina. In: Amerikanistische Studien - Estudios Americanistas, Libro Jubilar en homenaje a Hermann Trimborn II: 40-49; St. Agustin: Collectanea Instituti Anthropos 21.

MENDOZA ESPAÑA, V., 1997 - Informe de excavaciones arqueológicas en el sitio de Achiri. In: Informe Final. Proyecto arcaico-formativo en el altiplano del Departamento de La Paz - Investigaciones arqueológicas en el Cantón Achiri de la provincia Pacajes: 140176; La Paz: Universidad Mayor de San Andrés, carrera de antropología y arqueología. Manuscrito.

MERCADO DE PEÑALOSA, P. de, 1885 [1585-1589] - Relación de la provincia de los Pacajes. In: Relaciones Geográficas de Indias, t. II: 51-64; Madrid: Ministerio de Fomento.

MESA, J., CÉSPEDES, R., RICHARD, F. \& RIVERA, E., 1999 - Leónce Angrand: Un diplomático francés en Bolivia (1847-1849), 192 p.; La Paz: Total Exploration Production Bolivia Alianza Francesa - Instituto Francés de Estudios Andinos- IRD - Embajada de Francia en Bolivia - Colegio franco boliviano Alcides d'Orbigny.

MONTAÑO ARAGÓN, M., 1992 - Guía etnográfica lingüística de Bolivia (tribus del altiplano y valles), primera parte, t. III, 494 p.; La Paz: Editorial Don Bosco.

MONTAÑO ARAGÓN, M., 1999 - Mama Pacha: Diccionario de mitología Aymara, 600 p.; La Paz: Producciones CIMA.

MOORE, J. D., 2004 - The Social Basis of Sacred Spaces in the Prehispanic Andes: Ritual Landscapes of the Death in Chimú and Inka Societies. Journal of Archaeological Method and Theory, 11 (1): 83-124.

MORRIS, C. \& VON HAGEN, A., 1993 - The Inka Empire and Its Andean Origins, 251 p.; New York: American Museum of Natural History, Abbeville Press.

MOSELEY, M. E., 1992 - The Incas and their Ancestors. The Archaeology of Peru, 272 p.; London - New York: Thames and Hudson.

MOURGUIART, P., ARGOLLO, J., CARBONEL, P., CORREGE, T. \& WIRRMANN, D., 1995 - El lago Titicaca durante el Holoceno: una historia compleja. In: Climas cuaternarios en América del Sur: 173-188; La Paz: ORSTOM.

MUJICA BARREDA, E., 1985 - Altiplano-Coast Relationships in the South-Central Andes: From Indirect to Direct Complementarity. In: Andean Ecology and Civilization. An Interdisciplinary Perspective on Andean Ecological Complementarity: 103-140; University of Tokyo Press, Japan.

MUÑOZ OVALLE, I., 1996 - Asentamientos e interrelaciones culturales: Una aproximación al proceso prehispánico tardío en la Sierra de Arica. Tawantinsuyu. An International Journal of Inka Studies, 2: 44-58.

MUÑOZ OVALLE, I., 1998 - La expanción incaica y su vinculación con las poblaciones de los valles occidentales del extremo norte de Chile. Tawantinsuyu. An International Journal of Inka Studies, 4: 127-137.

MUÑOZ OVALLE, I., CHACAMA, J. M., ESPINOSA, G. V. \& BRIONES, M., 1987 - La ocupación tardía de Zapahuira y su vinculación a la organización económica y social inca. Chungará, 18: 67-89.

MURRA, J. V., 1988 - El Aymara libre de ayer. In: Raíces de América: el mundo Aymara: 51-73; Madrid: Alianza Editorial - Unesco.

MURRA, J. V., 1991 - Visita de los valles de Sonqo, 687 p.; Madrid: Instituto de Cooperación Iberoamericana, Sociedad Estatal Quinto Centenario. Monografias Economía Quinto Centenario.

NIELSEN, A., 1998 - Evidencias de larga duración en la ocupación humana del altiplano de Lipez (Potosí, Bolivia). In: Los desarrollos locales y sus territorios. Arqueología del nor y sur de Bolivia: 65-102; Jujuy: Universidad Nacional de Jujuy.

NORDENSKIÖLD, E., 1953 - Investigaciones arqueológicas en la region fronteriza de Perú y Bolivia, 170 p.; La Paz: Biblioteca Paceña Alcaldía Municipal. 
PALACIOS ALCOBA, G., 1997 - Informe de investigación arqueólogica. Proyecto Achiri. In: Informe Final. Proyecto arcaico-formativo en el altiplano del Departamento de La Paz - Investigaciones arqueológicas en el Cantón Achiri de la provincia Pacajes: 3-53; La Paz: Universidad Mayor de San Andrés, carrera de antropología y arqueología. Ms.

PÄRSSINEN, M., 1992 - Tawantinsuyu. The Inca State and Its Political Organization, 462 p.; Studia Historica 43, Societas Historica Finlandiae: Helsinki.

PÄRSSINEN, M., 1993 - Torres funerarias decoradas en Caquiaviri. Pumapunku, Nueva Época 5-6: 9-31.

PÄRSSINEN, M., 1997 - Investigaciones arqueológicas con ayuda de fuentes históricas: Experiencias en Cajamarca, Pacasa y Yampará. In: Saberes y Memorias en los Andes. In Memoriam Thierry Saignes: 41-58; Paris - Lima: Institut des Hautes Études de I'Amérique Latine - Instituto Francés de Estudios Andinos.

PÄRSSINEN, M., 2003 - Copacabana ¿el Nuevo Tiwanaku? Hacia una comprensión multidisciplinaria sobre las secuencias culturales post-tiwanacotas de Pacasa, Bolivia. In: Los Andes: cincuenta años después (1953-2003) Homenaje a John Murra: 229-280; Lima: Pontificia Universidad Católica del Perú.

PÄRSSINEN, M., 2005 - Caquiaviri y la provincia Pacasa: Desde el Alto-Formativo hasta la Conquista Española (1-1533), 318 p.; La Paz: UMSA - Colegio Nacional de Historiadores de Bolivia - Cima Editores. Colección Maestría en Historias Andinas y Amazónicas, vol. 6.

PÄRSSINEN, M. \& SIIRIÄINEN, A., 1997 - Inka-Style Ceramics and their Chronological Relationship to the Inka Expansion in the Southern Lake Titicaca Area (Bolivia). Latin American Antiquity, 8 (3): 255-271.

PATRONES DE LA PAZ, 1684 - Guarina: fols. 87r.- 94r. In: Patrones de La Paz 1579-1684/4, Sala 13:17-2-3; Buenos Aires: Archivo General de la Nación. Ms.

PLATT, T., 1988 - Pensamiento político Aymara. In: Raíces de América. El mundo Aymara: 365450; Madrid: Alianza Editorial - Unesco.

PLAZA MARTíNEZ, R., 2003 - Memoria profesional; significación morfológica de las chullpas de Culli Cullip, 57 p. +16 figs. Tesis de licenciatura, Universidad Mayor de San Andrés, Facultad de Ciencias Sociales, carrera de Arqueología.

PLAZA MARTíNEZ, R. \& PLAZA MARTíNEZ, V. W., 2000 - Informe de trabajo de campo presentado a la DINAAR, 25 p.; La Paz. Ms.

PONCE SANGINÉS, C., 1958 - Investigaciones arqueológicas en Salla. Khana, 27-30: 6-32; La Paz.

PONCE SANGINÉS, C., 1959 - Las tumbas de adobe de Totora. Khana, 33-34: 1-23; La Paz.

PONCE SANGINÉS, C., 1981 - Tiwanaku: espacio, tiempo y cultura, cuarta edición, 255 p.; La Paz - Cochabamba: Editorial Los Amigos del Libro.

PONCE SANGINÉS, C., 1993 - Investigaciones arqueológicas en Salla y Totora. Pumapunku, Nueva Época, 5-6: 89-162; La Paz.

PONCE SANGINÉS, C. \& LINARES ITURRALDE, E., 1966 - Comentario antropológico acerca de la determinación paleoserológica de grupos sanguíneos en momias prehispánicas del altiplano boliviano, 30 p.; La Paz: Academia Nacional de Ciencias de Bolivia. Publicación $\mathrm{n}^{\circ} 15$.

PORTUGAL ORTIZ, M., 1988 - Informe de la prospección a Pacajes (Etapa 1). Arqueología Boliviana, 3: 109-117; La Paz: Instituto Nacional de Arqueología.

POSNANSKY, A., 1957 - Tihuanacu: la cuna del hombre americano - The cradle of American man. t. III-IV, 275 p.; La Paz: Ministerio de Educación.

PUCHER, L., 1947 - Donde duerme el hijo del Sol. 'Mundial' visita las tumbas sagradas de KulliKulli en las cuales se conservan los restos de los incas que perecieron en las primeras batallas de America. Periódico «Mundial», 20 (146): 6.

RAMOS GAVILÁN, A., 1976 [1621] - Historia de Nuestra Señora de Copacabana, 254 p.; La Paz: Academia Boliviana de la Historia. Segunda edición completa, según la impresión príncipe de 1621. 
RECIO DE LEÓN, J., 1906 [1623] - Descripción del Paititi y provincias de Tipuani, Chunchos, etc. In: Juicio de límites entre el Perú y Bolivia. Prueba peruana presentado por Víctor M. Maurtua: Gobernaciones de Álvarez Maldonado y Laegui Urquiza, t. VI: 242-257; Barcelona.

RIVERA, M. A., 1991 - The Prehistory of Northern Chile: A Synthesis. Journal of World Prehistory, 5 (1): $1-47$.

RIVERA CASANOVAS, C., 1990 - Las torres funerarias de Viscachani. Textos Antropológicos, 1: 79-92; La Paz.

RIVERA C., S. \& PLATT, T., 1978 - El impacto colonial sobre un pueblo Pakaxa: La crisis del cacicazgo en Caquingora (Urinsaya), durante el siglo XVI. Avances. Revista boliviana de estudios históricos y sociales, 1: 101-120.

ROWE, J. H., 1995 - Behavior and Belief in Ancient Peruvian Mortuary Practice. In: Tombs for the Living: Andean Mortuary Practices: 27-41; Washington, D. C.: Dumbarton Oaks Research Library and Collection.

RYDÉN, S., 1947 - Archaeological Researches in the Highlands of Bolivia, 562 p.; Göteborg: Elanders Boktryckeri AB.

RYDÉN, S., 1957 - Andean Excavations I, The Tiahuanaco Era East of Lake Titicaca, 199 p.; Stockholm: The Ethnographical Museum of Sweden (Statens Etnografiska Museum). Monograph Series, Publications $\mathrm{n}^{\circ} 4$.

RYDÉN, S., 1959 - Andean Excavations II, Tupuraya and Cayhuasi: Two Tiahuanaco Sites, 122 p.; Stockholm: The Ethnographical Museum of Sweden, Stockholm (Statens Etnografiska Museum). Monograph Series, Publications $n^{\circ} 6$.

SAGÁRNAGA MENESES, J. A., 1997 - Proyecto Amaya Uta '97: Consideraciones generales. In: Proyecto arqueológico Amaya Uta '97: 1-38; La Paz. Informe presentado a la Dirección Nacional de Arqueología y Antropología (DINAAR). Manuscrito.

SAGÁRNAGA MENESES, J. A., 1999 - Proyecto Chullpa Pacha '98: Informe de labores, 104 p.; La Paz. Informe presentado a la Dirección Nacional de Arqueología y Antropología (DINAAR). Manuscrito.

SARMIENTO DE GAMBOA, P., 1943 [1572] - Historia de los Incas. Segunda edición, 301 p.; Buenos Aires: Emecé Editores, S.A.

SAVOY, G., 1970 - Antisuyo: The search for the lost cities of the Amazon, 211 p.; New York: Simon and Schuster.

SCHIAPPACASSE F., V., CASTRO R., V. \& NIEMEYER F., H., 1989 - Los desarrollos regionales en el Norte Grande. In: Culturas de Chile. Prehistoria desde sus orígenes hasta los albores de la conquista:181-220; Santiago de Chile: Editorial Andrés Bello.

SEVER, J., 1921 - Chullpas des environs de Pucará (Bolivie). Journal de la Société des Américanistes, XIII, I: 55-58.

SQUIER, E. G., 1973 [1877] - Peru, Incidents of Travel and Exploration in the Land of the Incas, 599 p.; New York: AMS.

STUIVER, M. \& REIMER, P. J., 1993 - Extended 14C Data Base and Revised CALIB 3.0 14C Age Calibration Program. Radiocarbon: 0215-230 (revised CALIB 4.4, 2002).

SZYKULSKI, J., 1996 - El sitio arqueológico Churajón y el problema de su cronología. Andes: Boletín de la Misión Arqueológica Andina, 1: 201-219; Varsovia.

TANTALEÁN YNGA, H. \& PÉREZ MAESTRO, C., 2000 - Muerte en el altiplano andino. Investigaciones en la necrópolis inca de Cutimbo (Puno, Perú). Revista de arqueología, año XXI, 228: 26-37; Madrid.

TAPIA PINEDA, F., 1978 - Investigaciones arqueológicas en Kacsili. Pumapunku, 12: 7-37; La Paz.

TORERO, A., 1987 - Lenguas y pueblos altiplánicos en torno al siglo XVI. Revista Andina, $\mathbf{5}$ (2): 329-405. 
TRIMBORN, H., 1958 - Die Chullpas von Sica-Sica. In: Copenhagen: Proceedings of the $32^{\text {nd }}$ International Congress of Americanists Copenhagen 1956: 24-39.

TRIMBORN, H., 1967 - Archäologische Studien in den Kordilleren Boliviens III, 181 p.; Berlin: Baessler-Archiv, Neue Folge - Beiheft 5.

TSCHOPIK, M. H., 1946 - Some Notes on the Archaeology of the Department of Puno, Peru, 57 p. + X plates; Cambridge: Mass. Papers of the Peabody Museum of American Archaeology and Ethnology, Harvard University, vol. xxvii, $\mathrm{n}^{\circ} 3$.

VÁSQUEZ, E., 1937 - Las ruinas de Kachakacha. Revista del Museo Nacional, 6 (1): 52-57.

VILLAMOR, D., 1998 - Proyecto Chullpa Pacha '98: Informe osteológico, 34 p.; La Paz. Informe inédito presentado a la Dirección Nacional de Arqueología y Antropología (DINAAR).

VILLAMOR, D., 1999 - Proyecto Chullpa Pacha '98: Estudio osteológico, segunda parte, 43 p.; La Paz. Informe inédito presentado a la Dirección Nacional de Arqueología y Antropología (DINAAR).

VON HAGEN, A., 2002 - Los Chachapoya y la Laguna de los Cóndores, 56 p.; Perú, Amazonas: Museo Leymebamba.

VOVELLE, M., 1990 - Mourir autrefois, 251 p.; Gallimard. Collection Folio/Histoire.

WACHTEL, N., 1986 - Men of the water: the Uru problem (sixteenth and seventeenth centuries). In: Anthropological History of Andean Polities: 283-310; Cambridge: Cambridge University Press.

ZIÓLKOWSKI, M. S., 1997- Los juegos y las apuestas o «del origen de la propiedad (privada)». In: Arqueología, Antropología e Historia en los Andes. Homenaje a María Rostworowski: 301-319; Lima: Instituto de Estudios Peruanos - Banco Central de Reserva del Perú. 